\title{
Ferroelectricity in Layered Perovskites as a Model of Ultra-Thin Films
}

\author{
Masanori Fukunaga, Masaki Takesada, Akira Onodera* \\ Department of Physics, Hokkaido University, Sapporo, Japan \\ Email: "onodera@phys.sci.hokudai.ac.jp
}

Received 22 February 2016; accepted 9 August 2016; published 12 August 2016

Copyright (C) 2016 by authors and Scientific Research Publishing Inc.

This work is licensed under the Creative Commons Attribution International License (CC BY). http://creativecommons.org/licenses/by/4.0/

cC) (i) Open Access

\begin{abstract}
The instability of thin ferroelectric films is discussed based on the close similarity of dielectric properties between bulk Bi-layered perovskites and thin $\mathrm{BaTiO}_{3}$ films. The dielectric properties of pseudo-two-dimensional layered perovskites suggest that the bulk layered ferroelectric is a good model of ultra-thin ferroelectric film with a few perovskite units, free from any misfit lattice strain. It seems plausible that the ferroelectric interaction is still prominent but shows a crossover from ferroelectric to antiferroelectric along the unique $c$-axis (perpendicular to the film plane); with decreasing thickness, the ferroelectricity appears within the plane, which results in so-called "canted ferroelectricity". An extra relaxation mode induced by surface effect of thin films correlates with soft mode, which results in a new intermediate phase between the paraelectric and ferroelectric phases. These evidences may indicate no critical thickness even for ferroelectric ultrathin films.
\end{abstract}

\section{Keywords}

Ferroelectricity, Layered Oxide, Perovskite, Thin Film, Size Effect

\section{Introduction}

Ferroelectric compounds exhibit many attractive physical properties such as piezoelectricity, pyroelectricity, high-dielectric constant, non-linear optical effects and bistable nature. Therefore various works have been focused on integration of ferroelectric thin films into devices such as ferroelectric nonvolatile memory (FRAM), metal-oxide-semiconductor field-effect transistors (MOSFETs) and sensor devices [1]-[5]. Although ferroelectrics were embedded as a functional element in the form of thin films, our concern is whether the ferroelectricty can persist even in ultra-thin films or not. Since the ferroelectricty originates fundamentally from electrostatic

\footnotetext{
*Corresponding author.
}

How to cite this paper: Fukunaga, M., Takesada, M. and Onodera, A. (2016) Ferroelectricity in Layered Perovskites as a Model of Ultra-Thin Films. World Journal of Condensed Matter Physics, 6, 224-243. 
long-range force in dielectric media, it is important to know the exact size effect of thin films on ferroelectricity and the critical thickness where the ferroelectricity may disappear. However, various experiments of ferroelectric thin films have not been enough investigated because of its difficulty to grow a good quality of ultra-thin films and to estimate the effects of misfit strain due to their substrate. It is of fundamental interest in twodimensional structure of ferroelectric thin films experimentally and theoretically since early times [6]. There have been many attempts to study the size effect on ferroelectricity, leading to a rich literature of both experimental and theoretical works [7] [8]. Especially, studies of ferroelectric perovskites are activated and are promised as one of the best sources of ferroelectric thin films since the perovskite oxides show prominent high dielectric constants and piezoelectric properties.

The similarity of dielectric and structural features has been observed between $\mathrm{BaTiO}_{3}$ thin films and $\mathrm{Bi}$ layered perovskite compounds. This means that both materials have a common mechanism for ferroelectric activity. Among Bi-layered perovskites, $\mathrm{SrBi}_{2} \mathrm{Ta}_{2} \mathrm{O}_{9}$ (abbreviated as SBT) has been extensively studied as a candidate for ferroelectric non-volatile memory devices. Based on dielectric and structural similarities, it may be reasonable to consider that SBT is a good model for an ideal ferroelectric thin film, free from any misfit lattice strain. The close analogy between Bi-layered perovskites and ferroelectric thin films was pointed out simply in a previous paper [9]. In this review, we will discuss the ferroelectric stability in ultra-thin films in detail from the viewpoint of the nature of Bi-layered perovskites.

\section{2. $\mathrm{BaTiO}_{3}:$ Bulk Crystal and Thin Film}

We will simply introduce fundamentals of barium titanate, $\mathrm{BaTiO}_{3}$, in the form of bulk crystal and thin films. Perovskite oxides have a basic structure of $\mathrm{ABO}_{3}$, where $A$ and $B$ are cations. This structure has been considered to be a prototype for many ferroelectrics just as for ferromagnetic, semiconducting and superconducting materials, depending on the composition. The first perovskite oxide showed ferroelectricity was $\mathrm{BaTiO}_{3}$, which is cubic with space group Pm3m in the high-temperature paraelectric phase. It undergoes a ferroelectric phase transition at $409.5 \mathrm{~K}\left(T_{c}\right)$ and has a tetragonal structure $(\mathrm{P} 4 \mathrm{~mm})$ at room temperature. The characteristic features associated with this phase transition are known such as a large dielectric anomaly. The dielectric constant $(\varepsilon)$ is over 14,000 at $T_{c}$ (Figure 1 ) and follows the Curie-Weiss law, $\varepsilon=C /\left(T-T_{c}\right.$ ) with $C=14,000 \mathrm{~K}$ [10]. The saturated spontaneous polarization $\left(P_{s}\right)$ of the tetragonal phase is about $26 \mu \mathrm{C} / \mathrm{cm}^{2}$ along the tetragonal $c$-axis.

This phase transition has been explained by the so-called "soft mode theory" after Cochran where a transverse optic (TO) mode softens [11] [12]. The decrease in the frequency of TO mode $\left(\omega_{T O}\right)$ towards $T_{c}$ results in the large dielectric anomaly as we should remember the following LST (Lyddane-Sachs-Teller) relation,

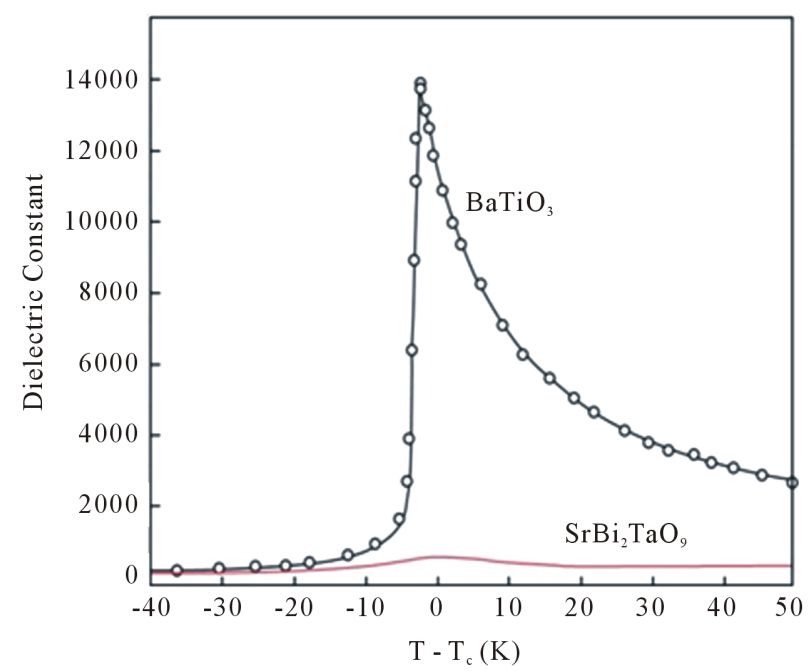

Figure 1. Dielectric constant of $\mathrm{BaTiO}_{3}$ bulk crystal associated with a paraelectric-ferroelectric phase transition [10]. The recent $T_{c}$ has been reported as $409.5 \mathrm{~K}$ in high quality sample as shown in Figure 4. The red line shows dielectric constants of $\mathrm{SrBi}_{2} \mathrm{TaO}_{9}$ bulk ceramics with $T_{c}=608 \mathrm{~K}$ [9]. 


$$
\frac{\varepsilon}{\varepsilon_{\infty}}=\prod_{j}\left(\frac{\omega_{\mathrm{LO} j}^{2}}{\omega_{\mathrm{TO} j}^{2}}\right)
$$

where $\varepsilon, \varepsilon_{\infty}$ are dielectric constant of static and at the frequency $f=\infty$. The $\omega_{\mathrm{LO}}$ and $\omega_{\text {TO }}$ are frequencies of longitudinal optic and transverse optic modes of the $j$-th branch, respectively.

Recently, however, it has been recognized that the dielectric constant begins to decrease with decreasing its sample thickness below $2000 \AA$ (Figure 2) [13]-[19]. The peak value of dielectric anomaly is only 380 at 1000 A. Moreover, the dielectric constant shows broad and non Cure-Weiss behavior as in Figure 3 [13]-[19]. This evidence indicates that the well-established soft mode may be modified in the sense of lattice dynamics of ultrathin films of $\mathrm{BaTiO}_{3}$.

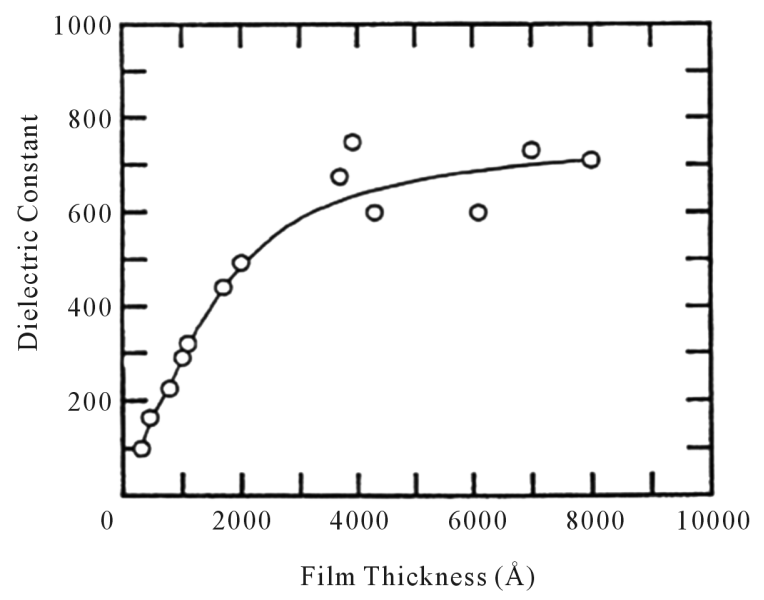

Figure 2. Thickness dependence of dielectric constant of $\mathrm{BaTiO}_{3}$ thin films on $\mathrm{Pt} / \mathrm{MgO}$ substrate at room temperature [13]-[19]. With decreasing thickness, the dielectric constant monotonically decreases from 700 (8000 $\AA$ thick) to 100 . The solid line is a guideline. Detailed discussion is given in reference [17].

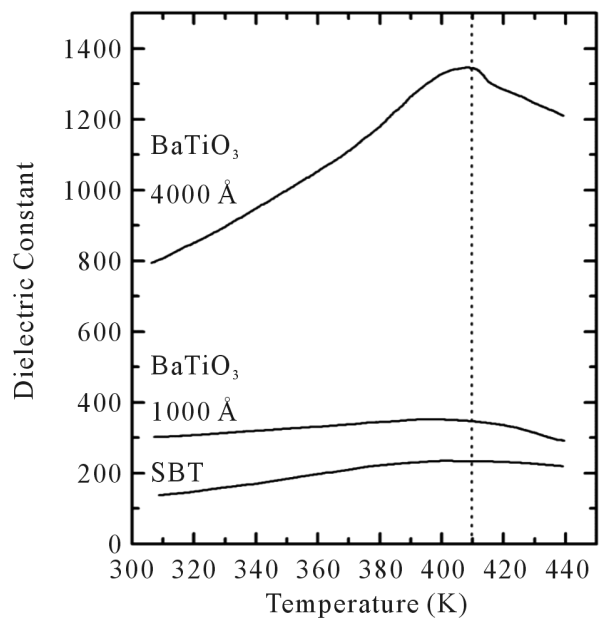

Figure 3. Temperature dependence of dielectric constant of $\mathrm{BaTiO}_{3}$ thin films with thickness of $4000 \AA$ and $1000 \AA$. Dielectric constant of $\mathrm{SrBi}_{2} \mathrm{Ta}_{2} \mathrm{O}_{9}$ (SBT) bulk ceramics is also referred for comparison where its $T_{C}$ is shifted to that of $\mathrm{BaTiO}_{3}$ bulk crystal [13]-[19]. The dotted line is the $T_{C}$ of $\mathrm{BaTiO}_{3}$ bulk crystal $\left(T_{c}=409.5 \mathrm{~K}\right)$. More detailed comparison is given in Figure 13. 
The specific heat $\left(C_{p}\right)$ shows a sharp and clear $\lambda$-type anomaly at $T_{\mathrm{c}}$ in bulk $\mathrm{BaTiO}_{3}$ [20]. In the case of thin films, it changes to a broad, small and characteristic one with decreasing film thickness [21]. The spontaneous polarization $\left(P_{s}\right)$ is related to the anomalous specific heat $\left(\Delta C_{p}\right)$ in the mean field theory as

$$
P_{s}^{2}(T)=\frac{C}{2 \pi} \int_{T}^{\infty} \frac{\Delta C_{p}}{T} \mathrm{~d} T
$$

This suggests that the temperature dependence of an order parameter (spontaneous polarization $P_{s}$ ) looks to be weak and linear. The upper and lower temperatures of anomalous specific part are shown by short arrows in Figure 5(a). Following the above thermodynamic relation, Equation (2), $T_{c}$ should be understood as the upper temperature, but it is rather difficult to determine $T_{c}$ definitely for this film. For film with $60 \AA$ thick, large hysteresis phenomena are observed as shown in Figure 5(b). The sharp anomalous specific heat observed in the single bulk crystal changes to diffuse one in thin films. It plays somewhat in different and diffusive manners from the usual mean-field behavior $\left(P_{s} \sim\left(T-T_{\mathrm{c}}\right)^{1 / 2}\right)$. As pointed out by many researches, these novel ferroelectric properties are essentially due to the two-dimensionality in thin films.

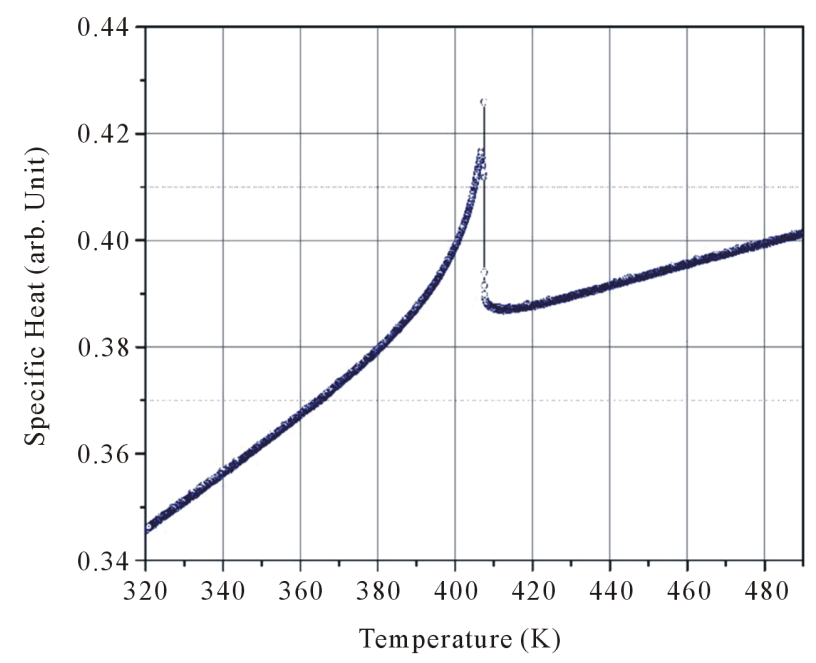

Figure 4. Temperature dependence of specific heat of $\mathrm{BaTiO}_{3}$ bulk single crystal around the paraelectric-ferroelectric phase transition point $T_{c}(409.5 \mathrm{~K})$ [20].

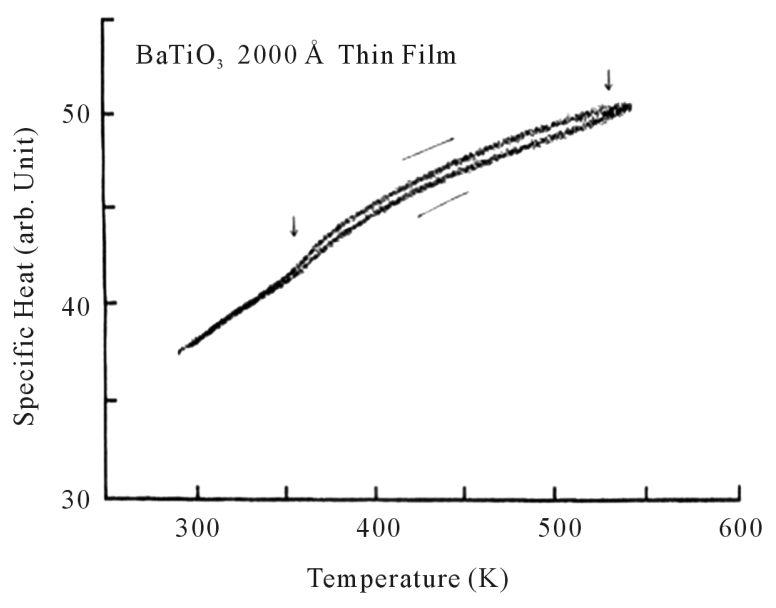

(a)

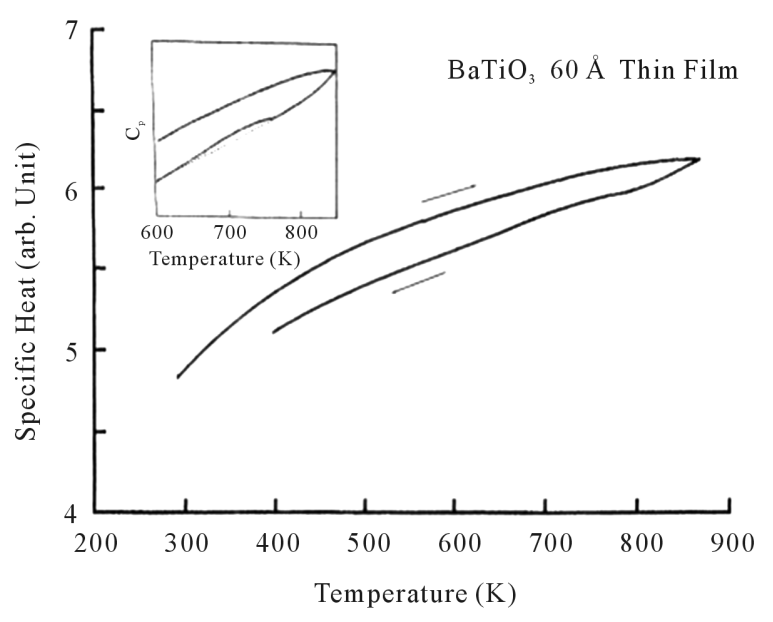

(b)

Figure 5. Temperature dependence of specific heat of $\mathrm{BaTiO}_{3}$ epitaxial thin films on $\mathrm{SrTiO}_{3}$ substrate; (a) $2000 \AA$ thick and (b) $60 \AA$ thick [21]. The arrows show the direction of heating and cooling. The short arrows indicate the beginning and end temperature of anomalous specific heat in (a). 
The similar weak dielectric nature has been pointed out in Bi-layered perovskite compounds [9] $\mathrm{SrBi}_{2} \mathrm{Ta}_{2} \mathrm{O}_{9}$ (SBT), which has been extensively studied as a candidate for ferroelectric non-volatile memory devices. As discussed in the next section, this similarity of crystal structure and dielectric properties between thin films of Ba$\mathrm{TiO}_{3}$ and $\mathrm{Bi}$-layered perovskites shows that both materials have a common mechanism resulted in dielectric nature. Moreover it suggests us that SBT may be a good model for an ideal ferroelectric thin film, though SBT itself is a bulk crystal.

\section{Bi-Layered Perovskite}

A series of layered perovskite compounds were discovered by Aurivillius in 1949 [22]. Among these compounds, the ferroelectric activities of Bi-layered perovskites were first discovered by Smolenskii et al. [23]. The general chemical formula of Bi-layered perovskites is $A_{m-1} \mathrm{Bi}_{2} B_{m} \mathrm{O}_{3 m+3}$, which is rewritten as $\left[\mathrm{Bi}_{2} \mathrm{O}_{2}\right]^{2+} \cdot\left[A_{m-1} B_{m} \mathrm{O}_{3 m+1}\right]^{2-}$. It consists of the regular staking of semiconducting $\left[\mathrm{Bi}_{2} \mathrm{O}_{2}\right]$ slabs and perovskite-like octahedral $\left[\mathrm{BO}_{6}\right]$ groups, as described by Haeni et al. [24]. Various $A$ and $B$ cations are allowed for these compounds such as $A=\mathrm{Na}^{+}, \mathrm{K}^{+}$, $\mathrm{Ba}^{2+}, \mathrm{Ca}^{2+}, \mathrm{Pb}^{2+}, \mathrm{Sr}^{2+}, \mathrm{Bi}^{3+}$, and $B=\mathrm{Fe}^{3+}, \mathrm{Ti}^{4+}, \mathrm{Nb}^{5+}, \mathrm{Ta}^{2+}, \mathrm{W}^{6+}$. For example, $\mathrm{Bi}_{2} \mathrm{WO}_{6}(m=1), \mathrm{SrBi}_{2} \mathrm{Ta}_{2} \mathrm{O}_{9}(m=$ $2)$ and $\mathrm{Bi}_{4} \mathrm{Ti}_{3} \mathrm{O}_{12}(m=3)$ are well studied. Additional members can be generated by allowing the number of stacking $(m)$ of perovskite-like group. The family of Bi-layered perovskites has the face-centered orthorhombic unit cell as shown in Figure 6.

The reported Bi-layered perovskites are summarized in Table 1 [25] [26]. The unit cell is highly anisotropic and pseudo two-dimensional as given in Table 2. The -O-B-O- $\mathrm{B}$-O- linkage along the pseudo-tetragonal unique $c$-axis is interrupted by the existence of semiconducting $\mathrm{Bi}_{2} \mathrm{O}_{2}$ layers. The perovskite $\mathrm{BO}_{6}$ layers and $\mathrm{Bi}_{2} \mathrm{O}_{2}$ layers are linked by weak van der Waals interaction. This structure is similar to that of thin perovskite films with

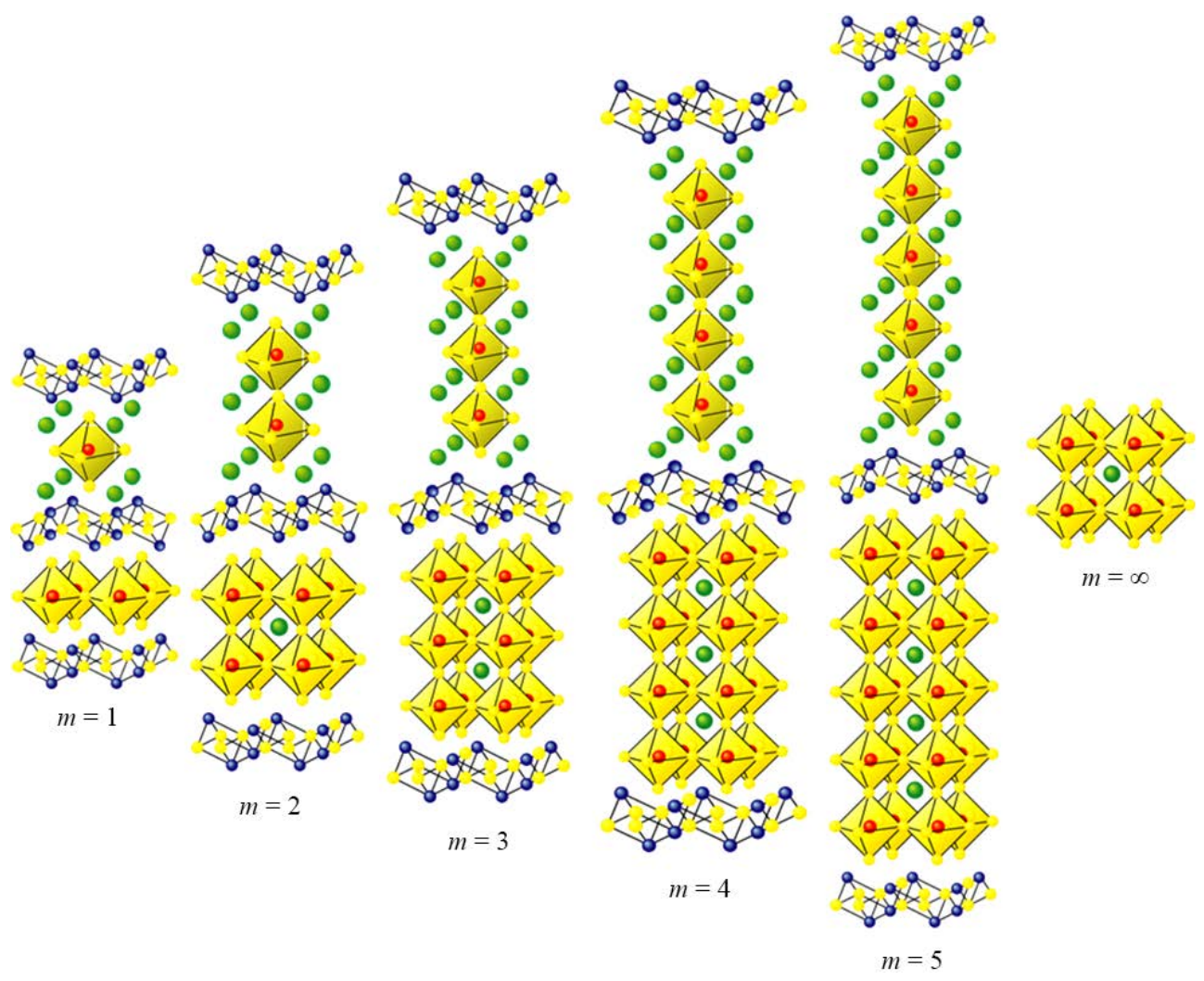

Figure 6. Crystal structures of Bi-layered perovskites depending on stacking number $(m)$ of perovskite-like groups. The atoms in $A_{m-1} \mathrm{Bi}_{2} B_{m} \mathrm{O}_{3 m+3}$ within the unit cell are shown as green ball $(A)$, red ball $(B)$, yellow ball $(\mathrm{O})$ and blue ball $(\mathrm{Bi})$. The long axis is the $c$-axis. The crystal structure is orthorhombic but nearly tetragonal at room temperature. The $\mathrm{BO}_{6}$ are shown as octahedra. $\mathrm{Bulk}^{\mathrm{BaTiO}} \mathrm{B}_{3}$ with simple perovskite structure has been recognized as a structure with expanded Bi-layered perovskite with infinity perovskite units $(m=\infty)$. 
Table 1. Dielectric properties of layered perovskites $\left(\mathrm{Bi}_{2} \mathrm{O}_{2}\right)^{2+}\left(\mathrm{A}_{m-1} \mathrm{~B}_{m} \mathrm{O}_{3 m+1}\right)^{2-}$. Ferroelectricity has not been confirmed.

\begin{tabular}{|c|c|c|c|c|c|c|c|}
\hline \multirow{2}{*}{$m$} & \multirow{2}{*}{ Compound } & \multirow{2}{*}{$T_{c}(\mathrm{~K})$} & \multirow{2}{*}{$\begin{array}{l}P_{s}\left(\mu \mathrm{C} / \mathrm{cm}^{2}\right) \\
\text { along } a \text { axis }\end{array}$} & \multicolumn{2}{|c|}{ Dielectric Constant } & \multicolumn{2}{|c|}{ Curie-Weiss Constant } \\
\hline & & & & $\varepsilon$ (r.t.) & $\varepsilon\left(T_{c}\right)$ & $C\left(10^{5} \mathrm{~K}\right)$ & $\Theta(\mathrm{K})$ \\
\hline 1 & $\mathrm{Bi}_{2} \mathrm{WO}_{6}$ & 973 & - & 200 & 3100 & 1.4 & 1199 \\
\hline 1 & $\mathrm{Bi}_{2} \mathrm{MoO}_{6}$ & 843 & - & 16 & 103 & - & - \\
\hline 2 & $\mathrm{Bi}_{3} \mathrm{TiNbO}_{9}$ & 1213 & - & 100 & - & - & \\
\hline 2 & $\mathrm{Bi}_{3} \mathrm{TiTaO}_{9}$ & $1146 ?$ & - & 140 & - & - & \\
\hline 2 & $\mathrm{CaBi}_{2} \mathrm{Nb}_{2} \mathrm{O}_{9}$ & $923 ?$ & - & 80 & - & - & \\
\hline 2 & $\mathrm{CaBi}_{2} \mathrm{Ta}_{2} \mathrm{O}_{9}$ & $873 ?$ & - & 140 & - & - & \\
\hline 2 & $\mathrm{SrBi}_{2} \mathrm{Nb}_{2} \mathrm{O}_{9}$ & 713 & - & 190 & 1100 & 0.55 & 663 \\
\hline 2 & $\mathrm{SrBi}_{2} \mathrm{Ta}_{2} \mathrm{O}_{9}$ & 608 & 5.8 at r. t. & 180 & 550 & 2.0 & 463 \\
\hline 2 & $\mathrm{BaBi}_{2} \mathrm{Nb}_{2} \mathrm{O}_{9}$ & 473 & - & 280 & 540 & - & - \\
\hline 2 & $\mathrm{BaBi}_{2} \mathrm{Ta}_{2} \mathrm{O}_{9}$ & 383 & - & 400 & 450 & - & - \\
\hline 2 & $\mathrm{PbBi}_{2} \mathrm{Nb}_{2} \mathrm{O}_{9}$ & 823 & - & 170 & 2100 & 1.3 & 783 \\
\hline 2 & $\mathrm{PbBi}_{2} \mathrm{Ta}_{2} \mathrm{O}_{9}$ & 703 & - & 180 & 340 & 0.37 & 598 \\
\hline 3 & $\mathrm{Bi}_{4} \mathrm{Ti}_{3} \mathrm{O}_{12}$ & 948 & $50 / / a, 4 / / c$ & 140 & 1600 & - & - \\
\hline 3 & $\mathrm{BaBi}_{3} \mathrm{Ti}_{2} \mathrm{NbO}_{12}$ & 543 & - & - & - & - & - \\
\hline 3 & $\mathrm{PbBi}_{3} \mathrm{Ti}_{2} \mathrm{NbO}_{12}$ & 563 & - & - & - & - & - \\
\hline 4 & $\mathrm{BaBi}_{4} \mathrm{Ti}_{4} \mathrm{O}_{15}$ & 693 & - & 150 & 1630 & 2.5 & 608 \\
\hline 4 & $\mathrm{PbBi}_{4} \mathrm{Ti}_{4} \mathrm{O}_{15}{ }^{*}$ & 843 & - & 220 & 5500 & 1.4 & 825 \\
\hline 4 & $\mathrm{SrBi}_{4} \mathrm{Ti}_{4} \mathrm{O}_{15}{ }^{*}$ & 803 & - & 190 & 1630 & 0.68 & 758 \\
\hline 4 & $\mathrm{CaBi}_{4} \mathrm{Ti}_{4} \mathrm{O}_{15}{ }^{*}$ & 1063 & - & 120 & - & - & - \\
\hline 4 & $\mathrm{Bi}_{5} \mathrm{Ti}_{3} \mathrm{CaO}_{15}$ & - & - & 150 & - & - & - \\
\hline 4 & $\mathrm{Na}_{0.5} \mathrm{Bi}_{4.5} \mathrm{Ti}_{4} \mathrm{O}_{15}$ & 908 & - & 200 & 1600 & 0.79 & 883 \\
\hline 4 & $\mathrm{~K}_{0.5} \mathrm{Bi}_{4.5} \mathrm{Ti}_{4} \mathrm{O}_{15}$ & 823 & - & 140 & 1700 & 0.74 & 788 \\
\hline 5 & $\mathrm{~Pb}_{2} \mathrm{Bi}_{4} \mathrm{Ti}_{5} \mathrm{O}_{18}$ & 583 & 0.06 at $508 \mathrm{~K}$ & 400 & 5900 & 4.1 & 553 \\
\hline 5 & $\mathrm{Sr}_{2} \mathrm{Bi}_{4} \mathrm{Ti}_{5} \mathrm{O}_{18}$ & 558 & 3.5 at $528 \mathrm{~K}$ & 280 & 1700 & 0.47 & 528 \\
\hline 5 & $\mathrm{Ba}_{2} \mathrm{Bi}_{4} \mathrm{Ti}_{5} \mathrm{O}_{18}$ & 602 & 2 at r.t. & 360 & - & - & - \\
\hline 5 & $\mathrm{Ca}_{2} \mathrm{Bi}_{4} \mathrm{Ti}_{5} \mathrm{O}_{18}$ & 726 & - & 40 & 420 & - & - \\
\hline 5 & $\mathrm{Pr}_{2} \mathrm{Bi}_{4} \mathrm{Ti}_{3} \mathrm{Fe}_{2} \mathrm{O}_{18}$ & 1173 & - & - & - & - & - \\
\hline 5 & $\mathrm{Bi}_{6} \mathrm{Ti}_{3} \mathrm{WO}_{18}$ & 1023 & - & 100 & 1000 & - & - \\
\hline
\end{tabular}

Table 2. Crystal system and the existence of soft mode of typical Bi-layered perovskites.

\begin{tabular}{cccc}
\hline$m$ & Compound & Crystal system (r.t.) & Lattice parameters (r.t.) $[\AA]$ \\
\hline 2 & $\mathrm{SrBi}_{2} \mathrm{Ta}_{2} \mathrm{O}_{9}$ & Orthorhombic $\left(\mathrm{A} 2_{1} \mathrm{am}\right)$ & $a=5.531, b=5.534, c=25.98$ \\
3 & $\mathrm{Bi}_{4} \mathrm{Ti}_{3} \mathrm{O}_{12}$ & Monoclinic $(\mathrm{Pc})$ & $a=5.450, b=5.406, c=32.83, \beta \sim 90^{\circ}$ \\
4 & $\mathrm{SrBi}_{4} \mathrm{Ti}_{4} \mathrm{O}_{15}$ & Orthorhombic $\left(\mathrm{A} 2_{1} \mathrm{am}\right)$ & $a=5.451, b=5.437, c=41.01$ \\
5 & $\mathrm{Sr}_{2} \mathrm{Bi}_{4} \mathrm{Ti}_{5} \mathrm{O}_{18}$ & Orthorhombic $(\mathrm{B} 2 \mathrm{cb})$ & $a=5.465, b=5.463, c=48.85$
\end{tabular}


$m$-layers. Among these compounds, $\mathrm{Bi}_{4} \mathrm{Ti}_{3} \mathrm{O}_{12}$ with $m=3$ has a monoclinic structure (Pc) and a polarization along the $a$ - and $c$-axis, which indicates that this crystal has an relatively strong interaction along the $c$-axis and shows the three-dimensional character. Therefore, compounds with $m=3\left(\mathrm{Bi}_{4} \mathrm{Ti}_{3} \mathrm{O}_{12}, \mathrm{BaBi}_{3} \mathrm{Ti}_{2} \mathrm{NbO}_{12}\right.$, and $\mathrm{PbBi}_{3} \mathrm{Ti}_{2} \mathrm{NbO}_{12}$ ) are not included in the following discussion on two-dimensional nature, although $\mathrm{Bi}_{4} \mathrm{Ti}_{3} \mathrm{O}_{12}$ is an interesting ferroelectric compound for thin film application.

\section{4. $\mathrm{SrBi}_{2} \mathrm{Ta}_{2} \mathrm{O}_{9}(\mathrm{SBT})$}

Strontium bismuth tantalate $\mathrm{SrBi}_{2} \mathrm{Ta}_{2} \mathrm{O}_{9}$ is the most important material in the application for FRAM, because of its low fatigue, low coercive field and $\mathrm{Pb}$-free compound [1] [2]. The room-temperature structure is orthorhombic A2 am ( $a=5.531, b=5.534, c=25.984 \AA)$, with 28 atoms in the unit cell. It consists of perovskite-type $\left[\mathrm{SrTa}_{2} \mathrm{O}_{7}\right]^{2-}$ groups (two layers of $\mathrm{TaO}_{6}$ octahedra) and semiconducting $\left[\mathrm{Bi}_{2} \mathrm{O}_{2}\right]^{2+}$ layers. They are stacked alternately along the pseudo- tetragonal $c$-axis as shown in Figure 7 [27]-[33]. Ferroelectricity in $\mathrm{SrBi}_{2} \mathrm{Ta}_{2} \mathrm{O}_{9}$ with $m$ $=2$ was discovered below $608 \mathrm{~K}\left(T_{\mathrm{c}}\right)$ by Smolenskii et al. in 1961 [23]. $\mathrm{SrBi}_{2} \mathrm{Ta}_{2} \mathrm{O}_{9}$ undergoes two phase transitions at $608 \mathrm{~K}$ and $850 \mathrm{~K}$. This crystal shows small and broad dielectric anomaly around $T_{c}$ where the maximum value is only 260 (Figure 8). A broad anomaly in specific heat has been observed as shown in Figure 9. This non Curie-Weiss like dielectric anomaly is observed not only in $\mathrm{SrBi}_{2} \mathrm{Ta}_{2} \mathrm{O}_{9}$ but also in other Bi-layered perovskites commonly.

The spontaneous polarization $\left(P_{s}\right)$ is relatively large and $5.8 \sim 10 \mu \mathrm{C} / \mathrm{cm}^{2}$ along the $a$-axis (not along the pseudo-tetragonal $c$-axis) at room temperature [25], while $P_{s}=26 \mu \mathrm{C} / \mathrm{cm}^{2}$ along the tetragonal $c$-axis in $\mathrm{BaTiO}_{3}$ [34].

The high-temperature paraelectric phase is tetragonal with space group I $4 / \mathrm{mmm}(a=3.927$, and $c=25.142 \AA$ at $1000 \mathrm{~K}$ ), where the $\mathrm{TaO}_{6}$ octahedra take antiparallel arrangements along the tetragonal $c$-axis [30]. The shape of $\mathrm{TaO}_{6}$ octahedron is not perfect and is elongated along the $c$-axis even in the paraelectric tetragonal phase, which means the $\mathrm{TaO}_{6}$ octahedon has a dipole moment. The Ta-O bond lengths owned commonly by adjacent octahedra along the tetragonal $c$-axis are a little bit short, and chemical bonds directed to $\mathrm{Bi}_{2} \mathrm{O}_{2}$-layer are long. In the ferroelectric phase, this crystal favors canted octahedral $\mathrm{TaO}_{6}$ arrangements below $T_{c}$. This structure results in the net spontaneous polarization along the $a$-axis and no polarization along the pseudo-tetragonal $c$-axis.

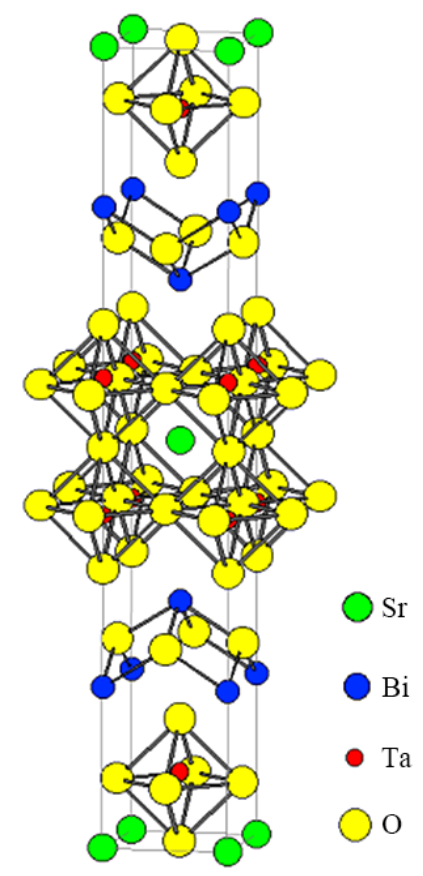

Figure 7. Crystal structure Bi-layered perovskite $\mathrm{SrBi}_{2} \mathrm{Ta}_{2} \mathrm{O}_{9}$, which consists of $\mathrm{Bi}_{2} \mathrm{O}_{2}$ semiconducting layers interleaved with $\mathrm{TaO}_{6}$ perovskite groups. This orthorhombic structure is nearly tetragonal with $a \sim b$. The $c$-axis is perpendicular to these stacking layers. 


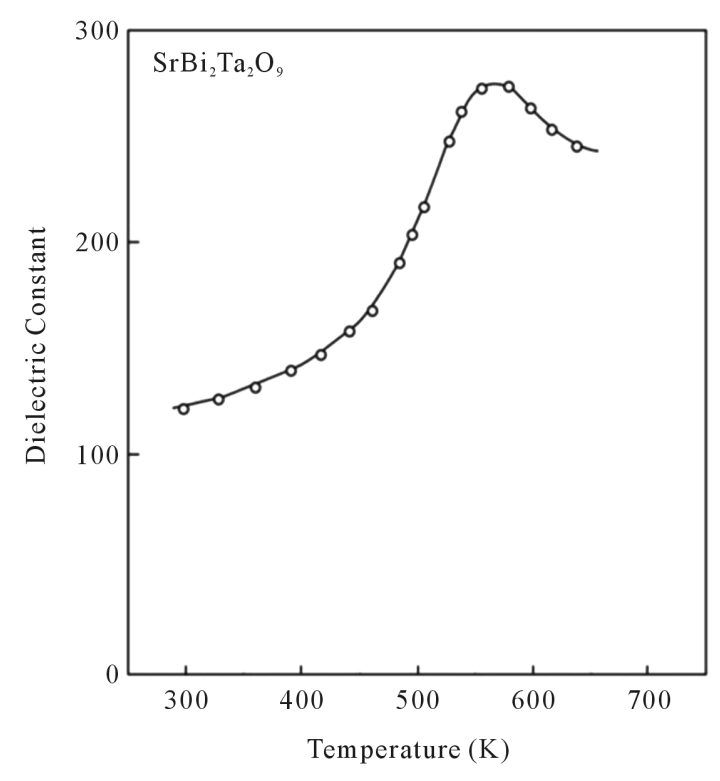

Figure 8. Small and broad dielectric behavior in $\mathrm{SrBi}_{2} \mathrm{Ta}_{2} \mathrm{O}_{9}$ around $T_{c}$. The peak value is only 260 and the half width of this anomaly is over $400 \mathrm{~K}$.

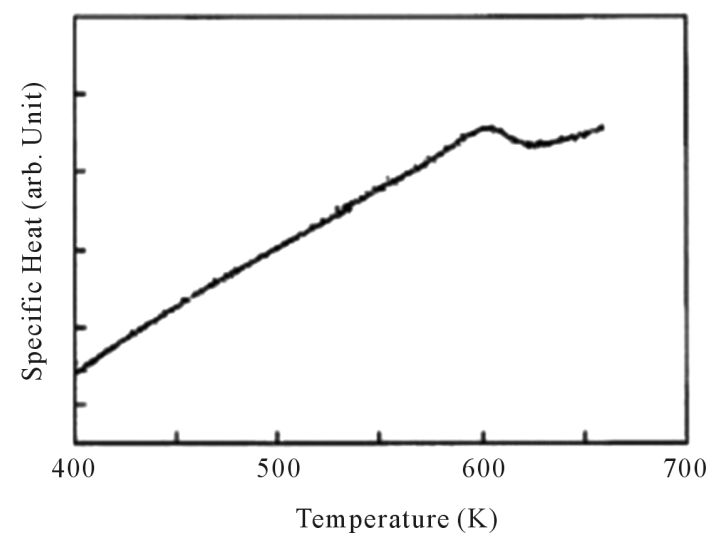

Figure 9. Temperature dependence of specific heat of $\mathrm{SrBi}_{2} \mathrm{Ta}_{2} \mathrm{O}_{9}$ single crystal [33].

The crystal structures of the high-temperature paraelectric phase at $1000 \mathrm{~K}$ and the ferroelectric phase at room temperature are schematically shown in Figure 10 [33] [35]-[38]. The $\mathrm{TaO}_{6}$ octahedra are distorted in both phases. Even in the high-temperature paraelectric phase, the octahedra are elongated along the pseudo-tetragonal $c$ axis and locate in an antiparallel way. The distortion parameter of one $\mathrm{TaO}_{6}$ octahedron, $p$, defined as

$$
p=|\boldsymbol{p}|=\sum_{i=1}^{7} q_{i}\left(\boldsymbol{r}_{i}-\boldsymbol{r}_{G}\right)
$$

is estimated to be 1.365 debye along the $c$-axis as shown in Table 3, where $q_{i}$ and $\boldsymbol{r}_{i}$ and are charge and position of each constituent ion, and $\boldsymbol{r}_{G}$ is the gravity center of $\mathrm{TaO}_{6}$ [30].

The parameter $\boldsymbol{p}$ is calculated as $(0,0,1.365)$ in debye unit in the high-temperature paraelectric phase. In the ferroelectric phase, the absolute value is 1.682 debye, which is almost the same as that of the high-temperature paraelectric phase within errors. If the distortion of octahedron corresponds to a dipole moment, it should be probable that $\mathrm{SrBi}_{2} \mathrm{Ta}_{2} \mathrm{O}_{9}$ prefers an antiferroelectric structure along the $c$-axis, when the distorted octahedra are mainly responsible for the ferroelectric activity. Furthermore, these distorted octahedra have a canted arrangement in the ferroelectric phase as shown in Figure 10(a). 


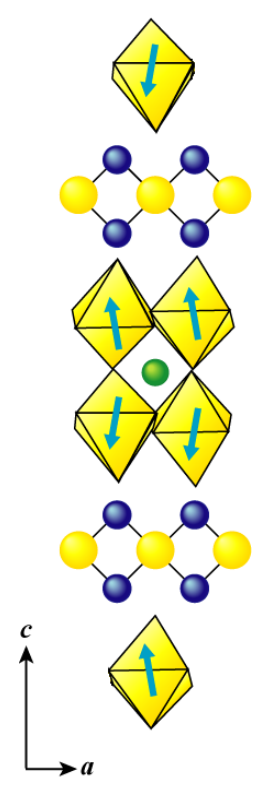

(a)

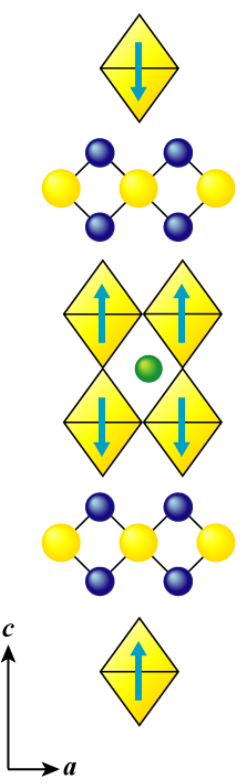

(b)

Figure 10. Schematic crystal structures of (a) the ferroelectric (space group; $\mathrm{A} 2{ }_{1} \mathrm{am}$ ) and (b) the paraelectric phases (space group; I4/mmm) of $\mathrm{SrBi}_{2} \mathrm{Ta}_{2} \mathrm{O}_{9}$. Arrows show estimated dipole arrangements of $\mathrm{TaO}_{6}$ octahedra [27].

Table 3. Estimated dipole moment of $\mathrm{TaO}_{6}$ octahedron of the ferroelectric phase at $300 \mathrm{~K}\left(\mathrm{~A} 2_{1} \mathrm{am}\right)$ and the high-temperature paraelectric phase (I4/mmm) at $1000 \mathrm{~K}$ [27].

\begin{tabular}{cccccc}
\hline & \multicolumn{3}{c}{ A2 $2_{1}$ am } & & I4/mmm \\
\cline { 2 - 6 } & Onodera [27] & Miura [37] & Shimakawa et al. [36] & Rae et al. [35] & Onodera [27] \\
\hline$p_{x}$ & 0.035 & 0.564 & 0.425 & 0.386 & 0 \\
$p_{y}$ & -0.702 & -0.074 & 0.001 & 0.003 & 0 \\
$p_{z}$ & 1.528 & 1.747 & 1.169 & 1.117 & 1.365 \\
$p$ & 1.682 & 1.837 & 1.244 & 1.182 & 1.365 \\
\hline
\end{tabular}

\section{Phase Transition in $\mathrm{SrBi}_{2} \mathrm{Ta}_{2} \mathrm{O}_{9}$}

The structural arrangement of $\mathrm{TaO}_{6}$ octahedra in SBT reminds us canted-ferromagnets (or weak ferromagnets) discussed by Moriya [39] and in layered canted-ferromagnets by de Gennes [40]. The free energy is given in terms of sublattice polarizations $P_{1}, P_{2}$ and an angle $\theta$ between them as

$$
F=\frac{1}{2} \alpha_{1} P_{1}^{2}+\frac{1}{2} \alpha_{2} P_{2}^{2}+\gamma P_{1} P_{2} \cos \theta-\delta P_{1} P_{2} \sin \theta,
$$

where the third symmetrical term is a well-known exchange interaction, which prefers an antiparallel configuration. The last term is an antisymmetric Dzialoshinski-Moriya interaction, which forces dipoles to tilt from the $c$-axis. These two terms are considered to be induced by the two-dimensional size effect of thin films. If $\theta=\pi$ and $\alpha_{1}=\alpha_{2}$, the above expression is the same as that for antiferroelectrics proposed by Kittel [41]. Because of the last Dzialoshinski-Moriya term, the above free energy favors the canted arrangement of dipoles rather than antiferroelectric one as shown in Figure 10(a).

From the condition, $\partial F / \partial \theta=0$, we get the following relation

$$
\tan \theta=-\delta / \gamma .
$$


As the observed value of $\theta$ is $154^{\circ}$ at room temperature, the coefficient $\delta$ of the antisymmetrical term is about half of the symmetrical term $\gamma$ in this compound. From the relations

$$
\partial F / \partial P_{1}=\partial F / \partial P_{2}=E,
$$

we have an expression for the dielectric susceptibility as

$$
\begin{aligned}
& \chi=\left(\alpha_{1}+\alpha_{2}-2 \gamma^{\prime}\right) /\left(\alpha_{1} \alpha_{2}-\gamma^{\prime 2}\right), \\
& \gamma^{\prime}=\gamma \cos \theta-\delta \sin \theta .
\end{aligned}
$$

When we assume $\alpha_{1}=\alpha_{2}=\alpha, \chi$ is given as

$$
\chi=2 /\left(\alpha+\gamma^{\prime}\right) .
$$

It is evident that the dielectric susceptibility shows a small cusp just like antiferroelectrics. As $\theta$ may vary from $\pi$ to $154^{\circ}$ with decreasing temperature, the coefficient $\gamma^{\prime}$ changes gradually. Dielectric constant may show a broad anomaly around $T_{c}$, which is smeared by two-dimensional surface strain as pointed out by Tagantsev et al. [42]. The weak dielectric behavior may be attributed to the two-dimensional effect, which favors for dipole moment to cant from the tetragonal axis in $\mathrm{SrBi}_{2} \mathrm{Ta}_{2} \mathrm{O}_{9}$.

\section{Dielectric Behavior in $\mathrm{Sr}_{2} \mathrm{Bi}_{4} \mathrm{Ti}_{5} \mathrm{O}_{18}$ with $m=5$}

The phase transitions in Bi-layered perovskites with $m=5$ have not been known in comparison to $\mathrm{SrBi}_{2} \mathrm{Ta}_{2} \mathrm{O}_{9}$. The crystal structure is orthorhombic with space group B2cb at room temperature (Figure 11) [43]. The high-temperature phase is believed to be tetragonal (I4/mmm). The dielectric measurement of $\mathrm{Sr}_{2} \mathrm{Bi}_{4} \mathrm{Ti}_{5} \mathrm{O}_{18}$ at frequencies of $1 \mathrm{kHz}, 10 \mathrm{kHz}$ and $100 \mathrm{kHz}$ was shown in Figure 12 [44]. Two dielectric anomalies of $\mathrm{Sr}_{2} \mathrm{Bi}_{4} \mathrm{Ti}_{5} \mathrm{O}_{18}$ were found at $551 \mathrm{~K}\left(T_{c}\right)$ and $730 \mathrm{~K}\left(T_{H}\right)$ although Mouri et al. reported dielectric anomalies at 428 $\mathrm{K}$ and $558 \mathrm{~K}$ [45]. The anomaly at $T_{c}$ is almost the same as reported by Subbarao [25]. The successive phase transitions were reported also in $\mathrm{Pb}_{2} \mathrm{Bi}_{4} \mathrm{Ti}_{5} \mathrm{O}_{18}$ with $m=5$ [45] [46]. Very little is known about dielectric behavior in Bi-layered perovskites, in particular, at high temperatures.

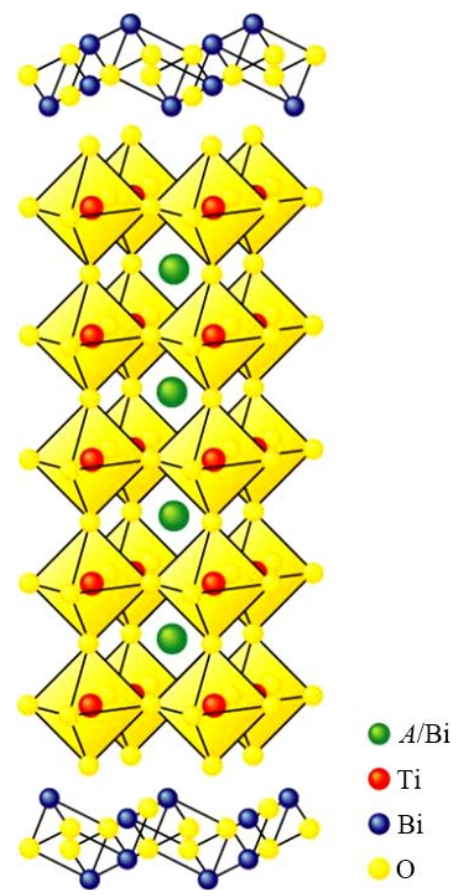

Figure 11. Crystal structure of Bi-layered perovskite $\mathrm{Sr}_{2} \mathrm{Bi}_{4} \mathrm{Ti}_{5} \mathrm{O}_{18}$ with $m=5$ (half of the unit cell). The $c$-axis is perpendicular to the stacking layers of $\mathrm{Bi}_{2} \mathrm{O}_{2}$ semiconducting layer and perovskite-like groups. 
The peak value of dielectric constant is about $1700(100 \mathrm{kHz})$ which is one order larger than $\mathrm{SrBi}_{2} \mathrm{Ta}_{2} \mathrm{O}_{9}(\varepsilon \sim$ $260)$ but smaller than that of $\mathrm{BaTiO}_{3}(\varepsilon \sim 14,000)$. The rather sharp dielectric anomaly was observed in the case of Bi-layered perovskites with $m=5$. This evidence is consistent with the Curie-Weiss behavior in soft mode of $\mathrm{Sr}_{2} \mathrm{Bi}_{4} \mathrm{Ti}_{5} \mathrm{O}_{18}$ discussed later.

\section{Similarities of Dielectric Properties of $\mathrm{BaTiO}_{3}$ Ultra-Thin Film and $\mathrm{SrBi}_{2} \mathrm{Ta}_{2} \mathrm{O}_{9}$}

Recently, Onodera et al. pointed out close similarities between Bi-layered perovskites and ferroelectric thin films, and discussed the ferroelectric instability in thin films with two-dimensionality [9] [47]. Figure 1 and Figure 13 show a comparison of dielectric behavior in bulk $\mathrm{BaTiO}_{3}$ crystal, $\mathrm{BaTiO}_{3}$ thin film $(1000 \AA)$ and Bi-layered perovskite $\mathrm{SrBi}_{2} \mathrm{Ta}_{2} \mathrm{O}_{9}$. The small and broad dielectric anomalies are commonly observed in $\mathrm{BaTiO}_{3}$ thin films and bulk $\mathrm{SrBi}_{2} \mathrm{Ta}_{2} \mathrm{O}_{9}$ crystal.

The decrease and non-clear behavior of dielectric constant were also observed around $T_{c}$ with decreasing film thickness in $(\mathrm{Ba}, \mathrm{Sr}) \mathrm{TiO}_{3}$ thin films. In this case, Hwang analyzed this decrease by considering the effects of a finite charge-screening length of metal electrodes and an intrinsic dead layer of the surface [48].

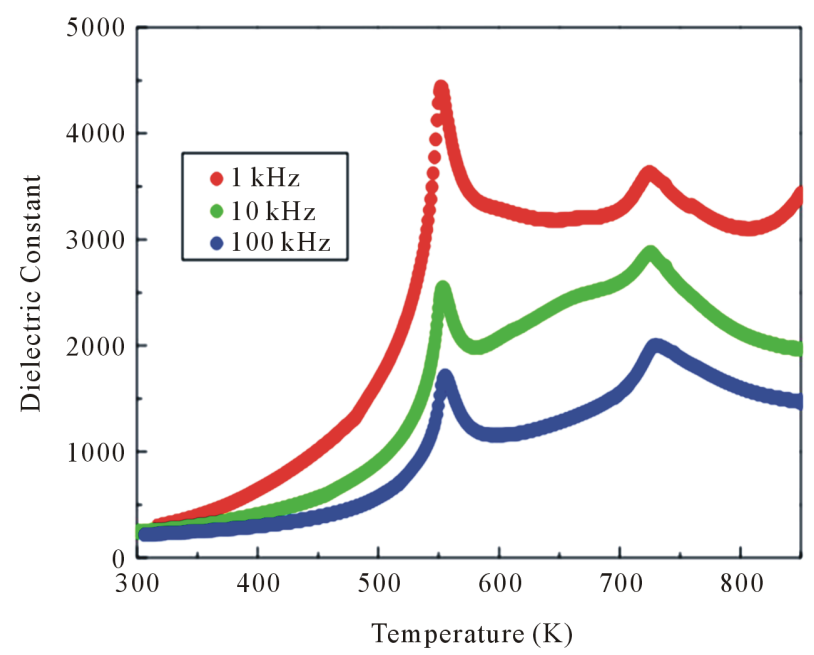

Figure 12. Dielectric constant of $\mathrm{Sr}_{2} \mathrm{Bi}_{4} \mathrm{Ti}_{5} \mathrm{O}_{18}$ at $1 \mathrm{kHz}, 10$ $\mathrm{kHz}$ and $100 \mathrm{kHz}$. Two clear anomalies were found at $551 \mathrm{~K}$ $\left(T_{c}\right)$ and $730 \mathrm{~K}\left(T_{H}\right)$.

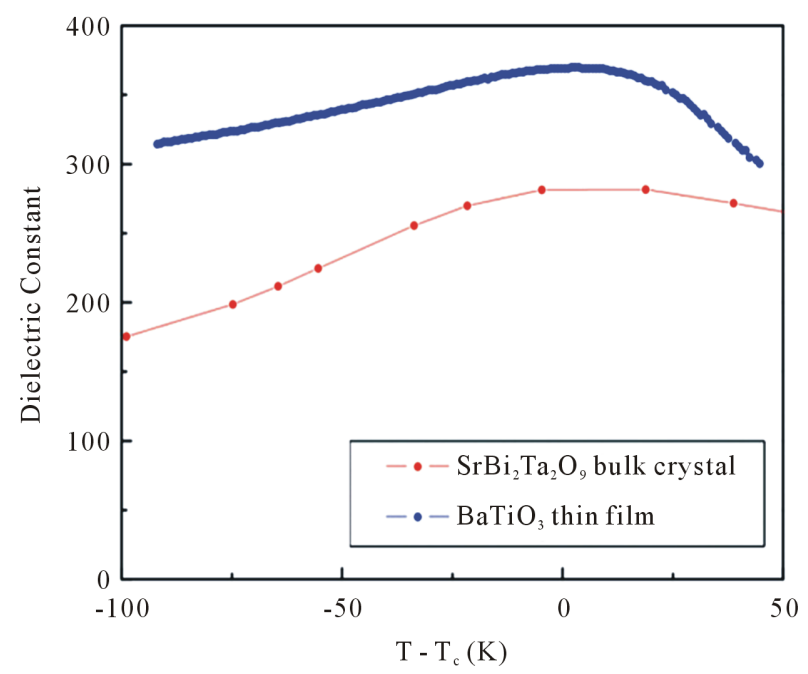

Figure 13. The dielectric constant versus $\left(T-T_{c}\right)$ of $\mathrm{BaTiO}_{3}$ thin films and bulk Bi-layered perovskite $\mathrm{SrBi}_{2} \mathrm{Ta}_{2} \mathrm{O}_{9}$. 
As discussed previously, the two-dimensional crystal structures are clear in both crystals. The crystal structure of Bi-layered perovskites is highly anisotropic along the pseudo-tetragonal $c$-axis. The single crystal of $\mathrm{SrBi}_{2} \mathrm{Ta}_{2} \mathrm{O}_{9}$ is easily cleaved along the pseudo-tetragonal $c$-axis, because the semiconducting $\mathrm{Bi}_{2} \mathrm{O}_{2}$ layer interacts weakly with upper and lower perovskite-like groups by van der Waals interaction. These dielectric and structural evidences may suggest the common mechanism for dielectric properties and the appearance of ferroelectricity for two crystals.

Experiments of Bi-layered perovskites are much easier than those of ultra-thin films because Bi-layered perovskites are bulk crystals. In addition, Bi-layered perovskites are free from misfit strain between ultra-thin film and substrate. The thickness was controlled by the stacking number of perovskite layers, $m$, of Bi-layered perovskites. The analogy in crystal structure and dielectric behavior between $\mathrm{BaTiO}_{3}$ ultra-thin films and Bi-layered perovskites may give us a perspective for the size effect and the ferroelectric nature of ultra-thin films.

\section{Soft Mode and Relaxation Behavior in Bi-Layered Perovskites}

The soft modes of Bi-layered perovskites were studied extensively for Sr-compounds with $m=2,4,5$, because Sr-compounds have a clear soft mode, while the exact crystal structures and phase transitions of this series of compounds have not been clarified yet.

\subsection{Soft Mode in $\mathrm{SrBi}_{2} \mathrm{Ta}_{2} \mathrm{O}_{9}(m=2)$}

The soft mode of $\mathrm{SrBi}_{2} \mathrm{Ta}_{2} \mathrm{O}_{9}$ has been studied by Raman scattering by several researchers [38] [49]-[52]. The square of soft mode frequency decreases toward to the highest phase transition temperature $T_{H}(850 \mathrm{~K})$ and shows a clear anomaly at $T_{c}(610 \mathrm{~K})$. The soft mode exists in the ferroelectric phase and shows highly overdamped behavior near $T_{c}$, although dielectric constant does not show any clear anomaly at $T_{c}$. An anomaly was detected in the share strain $c_{44}$ at $850 \mathrm{~K}$ [53], which corresponds to the high-temperature phase transition at $T_{H}$. The temperature dependence of $\omega_{s}^{2}$, the square of soft mode frequency, and the damping factor $\Gamma$ of $\mathrm{SrBi}_{2} \mathrm{Ta}_{2} \mathrm{O}_{9}$ are shown in Figure 14. The soft mode frequency does not follow the Curie-Weiss law. This soft mode disappears at $T_{c}$, which means that this mode becomes Raman inactive above $T_{c}$. The extrapolated temperature where this soft mode vanishes is $860 \mathrm{~K}$, just close to $T_{H}$.

In low frequency region from 0.3 to $1.7 \mathrm{~cm}^{-1}$, the relaxation mode of $\mathrm{SrBi}_{2} \mathrm{Ta}_{2} \mathrm{O}_{9}$ was observed which is generally observed in order-disorder type ferroelectrics [53]. The increase in intensity of relaxation mode was observed with increasing temperature towards $T_{c}$. This means that the soft mode exists even in Bi-layered compound with two perovskite layers, although an order-disorder nature is induced additionally.

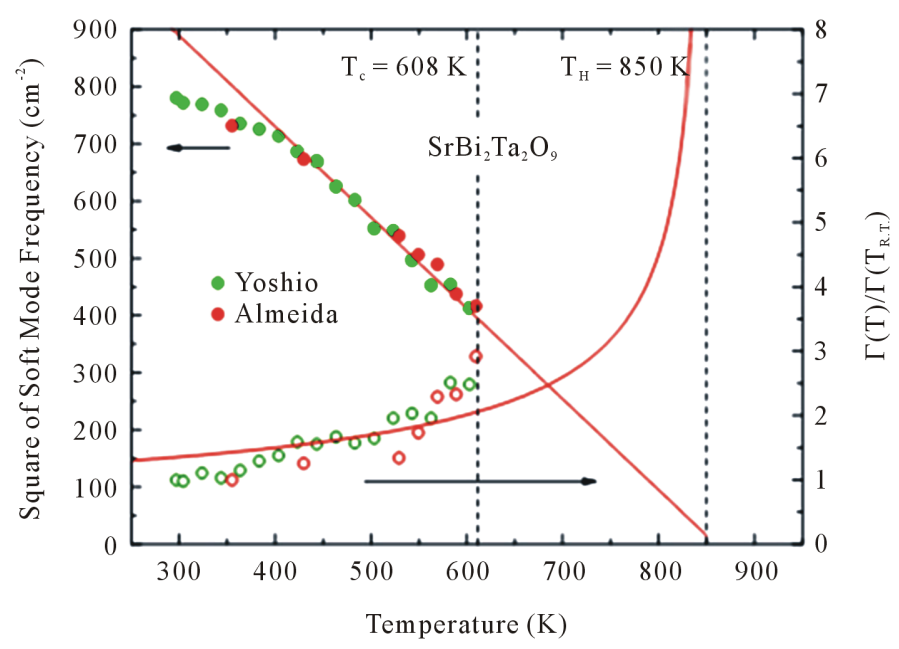

Figure 14. Temperature dependence of soft mode frequency and a normalized damping factor $\Gamma(\mathrm{T}) / \Gamma\left(\mathrm{T}_{\text {R.T. }}\right)$ in $\mathrm{SrBi}_{2} \mathrm{Ti}_{2} \mathrm{O}_{9}$ [38] [51] [52]. The phase transitions of $\mathrm{SrBi}_{2} \mathrm{Ta}_{2} \mathrm{O}_{9}$ are observed at $608 \mathrm{~K}\left(T_{c}\right)$ and $850 \mathrm{~K}\left(T_{H}\right)$. 


\subsection{Soft Mode in $\mathrm{SrBi}_{4} \mathrm{Ti}_{4} \mathrm{O}_{15}(m=4)$}

The crystal structure of Bi-layered perovskites with $m=4$ is orthorhombic ( $\left.\mathrm{A} 2{ }_{1} \mathrm{am}\right)$ at room temperature [54]. The rotation of $\mathrm{TiO}_{6}$ octahedra and displacement of $\mathrm{Ti}$ ions have been reported from their hypothetical tetragonal structure at high temperatures. The soft mode behavior of Bi-layered perovskites with $m=4$ was studied systematically by Kojima [55]. The ferroelectric-like phase transitions have been reported at $803 \mathrm{~K}$ for $\mathrm{SrBi}_{4} \mathrm{Ti}_{4} \mathrm{O}_{15}$ and $1063 \mathrm{~K}$ for $\mathrm{CaBi}_{4} \mathrm{Ti}_{4} \mathrm{O}_{15}$ respectively although the detailed series of phase transitions have not been confirmed yet. Figure 16 shows the temperature dependence of the square of the frequency $\omega_{s}^{2}$ of underdamped soft modes [55]. It is found that this soft mode was observed up to about $580 \mathrm{~K}$ but showed softening towards $T_{c}$ $=803 \mathrm{~K}$ as observed in $\mathrm{SrBi}_{2} \mathrm{Ta}_{2} \mathrm{O}_{9}$. Similar soft mode behavior was reported also in $\mathrm{CaBi}_{4} \mathrm{Ti}_{4} \mathrm{O}_{15}$.

The existence of an additional intermediate phase may be possible also for this series of compounds. The lattice parameters show slight kinks around $600 \mathrm{~K}$ for $\mathrm{SrBi}_{4} \mathrm{Ti}_{4} \mathrm{O}_{15}$ and $750 \mathrm{~K}$ for $\mathrm{CaBi}_{4} \mathrm{Ti}_{4} \mathrm{O}_{15}$ [54], although no detailed works have been done for phase transitions.

\subsection{Soft Mode in $\mathrm{Sr}_{2} \mathrm{Bi}_{4} \mathrm{Ti}_{5} \mathrm{O}_{18}(m=5)$}

The soft mode spectrum shows large temperature dependence at two temperatures, $T_{c}(551 \mathrm{~K})$ and $T_{H}(730 \mathrm{~K})$ [56]; the underdamped soft mode is clearly observed at room temperature, but changes to an overdamped one above $460 \mathrm{~K}$. The extrapolation of soft mode frequency and line width shows an anomaly at $T_{\mathrm{H}}$. Moreover, an additional relaxation mode due to an order-disorder nature was observed which may be induced by the twodimensionality in $\mathrm{Sr}_{2} \mathrm{Bi}_{4} \mathrm{Ti}_{5} \mathrm{O}_{18}$. In an order-disorder phase transition, the relaxation time diverges at $T_{c}$, and the HWHM (half width half maximum) becomes zero at $T_{c}$. This typical order-disorder character observed in $\mathrm{Sr}_{2} \mathrm{Bi}_{4} \mathrm{Ti}_{5} \mathrm{O}_{18}$ may be related to the layered structure, i.e. coupling of polarization fluctuation in intra-layer and inter-layer.

The similar behavior in soft modes is found in $\mathrm{SrBi}_{2} \mathrm{Ta}_{2} \mathrm{O}_{9}, \mathrm{SrBi}_{4} \mathrm{Ti}_{4} \mathrm{O}_{15}$ and $\mathrm{Sr}_{2} \mathrm{Bi}_{4} \mathrm{Ti}_{5} \mathrm{O}_{18}$ as shown in Figures 15-17. The plot of square frequencies of soft modes shows a change from the non Curie Weiss behavior to rather the Curie-Weiss like behavior. This tendency corresponds well to relatively large and sharp dielectric anomalies in $\mathrm{SrBi}_{4} \mathrm{Ti}_{4} \mathrm{O}_{15}$ and $\mathrm{Sr}_{2} \mathrm{Bi}_{4} \mathrm{Ti}_{5} \mathrm{O}_{18}$, with increasing the stacking layer $m$. Additional relaxation modes were observed in $\mathrm{SrBi}_{2} \mathrm{Ta}_{2} \mathrm{O}_{9}$ and $\mathrm{Sr}_{2} \mathrm{Bi}_{4} \mathrm{Ti}_{5} \mathrm{O}_{18}$. These evidences show that there are both displacive (soft mode) and order-disorder (relaxational) characters in Bi-layered perovskites. The effect due to an order-disorder character increases with decreasing $m$, which induce an extra intermediate phase between the high-temperature paraelectric and the low-temperature paraelectric phases. The nature of ferroelectricity in $\mathrm{BaTiO}_{3}$ has been investigated intensively since $\mathrm{BaTiO}_{3}$ has a simple $\mathrm{ABO}_{3}$ crystal structure and exhibits typical ferroelectric phase transitions. The soft mode theory has explained well dielectric properties [11] [12]. However, the order-disorder nature has

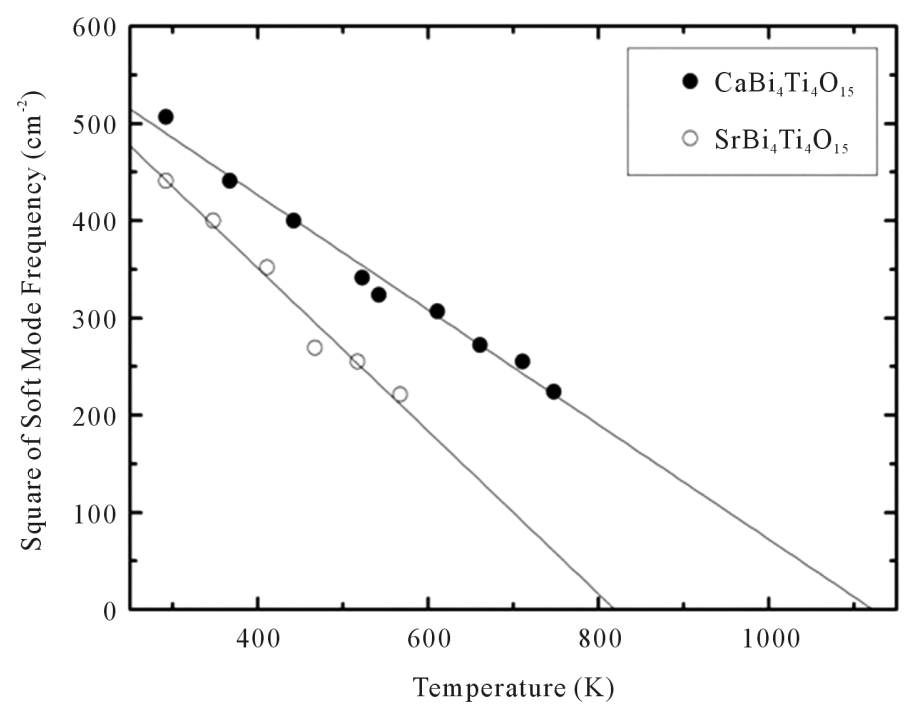

Figure 15. Temperature dependence of soft mode in $\mathrm{SrBi}_{4} \mathrm{Ti}_{4} \mathrm{O}_{15}$ and $\mathrm{CaBi}_{4} \mathrm{Ti}_{4} \mathrm{O}_{15}$ after Kojima [55]. 


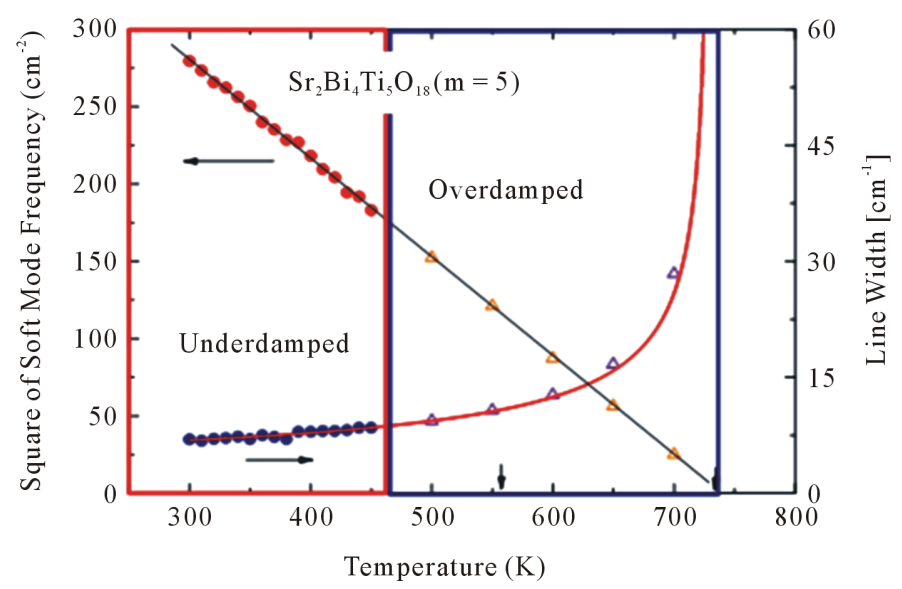

Figure 16. Temperature dependence of square frequency (red point) of soft mode and its line width (blue point) in $\mathrm{Sr}_{2} \mathrm{Bi}_{4} \mathrm{Ti}_{5} \mathrm{O}_{18}$ [56]. The solid line and red curve indicate the Curie-Weiss law and the universal scaling law, respectively.

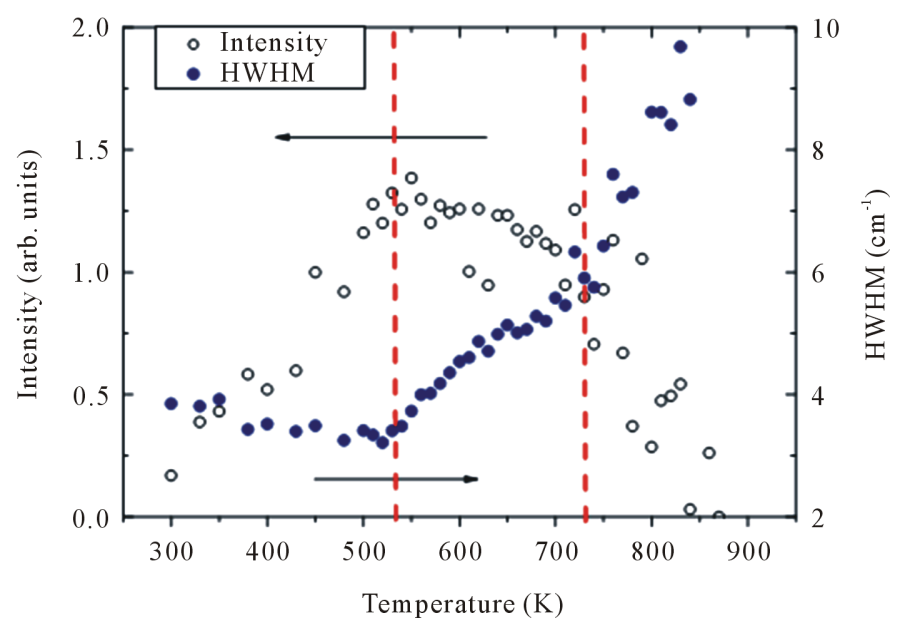

Figure 17. Intensity and HWHM (half width half maximum) of relaxation mode in $\mathrm{Sr}_{2} \mathrm{Bi}_{4} \mathrm{Ti}_{5} \mathrm{O}_{18}$ [56].

been reported in the critical region near $T_{c}$ observed by diffuse scattering in $\mathrm{BaTiO}_{3}$ [57]-[59]. Recent NMR study also showed the coexistence of both order-disorder and displacive components in $\mathrm{BaTiO}_{3}$ in the tetragonal ferroelectric to cubic paraelectric transition [60]-[62]. The delicate balance between the soft mode behavior and relaxational order-disorder component will compete and modify dielectric properties and the sequence of phase transitions as observed in ultra-thin perovskite films and Bi-layered perovskites.

\section{Ferroelectricity and Size Effect in Thin Films}

Ferroelectricity in Bi-layered perovskites $\mathrm{SrBi}_{2} \mathrm{Ta}_{2} \mathrm{O}_{9}, \mathrm{Sr}_{2} \mathrm{Bi}_{4} \mathrm{Ti}_{5} \mathrm{O}_{18}$ does not appear along the pseudo-tetragonal $c$-axis but along the $a$-axis normal to the pseudo-tetragonal axis, while along the tetragonal $c$-axis in $\mathrm{BaTiO}_{3}$. Crystal structure analysis of $\mathrm{SrBi}_{2} \mathrm{Ta}_{2} \mathrm{O}_{9}$ shows that $\mathrm{TaO}_{6}$ octahedra is still distorted along the pseudo-tetragonal $c$-axis, and locate in antiparallel way even in the high-temperature paraelectric phase above $850 \mathrm{~K}$. Although the -O-Ta-O-Ta-O- chain along the pseudo-tetragonal $c$-axis is interrupted by the existence of semiconducting $\mathrm{Bi}_{2} \mathrm{O}_{2}$ layers in $\mathrm{SrBi}_{2} \mathrm{Ta}_{2} \mathrm{O}_{9}$, the strongly correlated -O-Ta-O-Ta-O- chain should play an essential role for the appearance of ferroelectricity as those in $\mathrm{BaTiO}_{3}[63]$.

The shape of octahedron is not a regular octahedron even in the high-temperature paraelectric phase; this indicates that Bi-layered perovskites are antiferroelectric in the high-temperature tetragonal phase. In the ferroe- 
lectric phase, this crystal favors canted octahedral arrangements below $T_{c}$, which results in the net spontaneous polarization along the $a$-axis. This situation is just the same as that reported in the case of weak ferromagnetic materials.

On the other hand, this pseudo-two-dimensional character of crystal structure is just suitable for fabrication of thin films. The spontaneous polarization $\left(P_{s}\right)$ is relatively large $\left(5.8 \sim 10 \mu \mathrm{C} / \mathrm{cm}^{2}\right.$ along the $a$-axis at room temperature), while $P_{s}=26 \mu \mathrm{C} / \mathrm{cm}^{2}$ in a representative perovskite ferroelectric $\mathrm{BaTiO}_{3}$ along the tetragonal $c$-axis.

Ferroelectricity appears due to a delicate balance between long-range dipole-dipole interaction along the polar axis and short-range interaction. The typical dipolar correlation lengths for many ferroelectrics are $L_{c} \sim 10-50$ $\mathrm{nm}$ along the polar axis and $L_{a} \sim 1-2 \mathrm{~nm}$ normal to the polar axis [64]. The needle-shaped correlation region is sketched in Figure 18, where $L a$ is several unit-cells, of the same order as the thickness of a $180^{\circ}$ domain wall, and $L_{c}$ is about $25 \sim 125$ unit-cells in the case of $\mathrm{BaTiO}_{3}$. Therefore it is considered that the stability of the ferroelectricity may be affected by the thickness of the thin films.

Measurements of thickness dependence of ferroelectricity are generally not so easy, because of the preparation of good quality of thin films, additional surface effects such as depolarization fields and space-charge effects. These effects generally influence the ferroelectric behavior in thin films.

Tybell, Ahn and Triscone have examined the possibility of the existence of a critical thickness and showed the detection of the ferroelectricity in perovskite $\mathrm{Pb}\left(\mathrm{Zr}_{0.2} \mathrm{Ti}_{0.8}\right)_{3}$ films down to a thickness of 10 unit cells (40 $\AA$ ) [65]. Bune et al. reported ferroelectric activity in ferroelectric polymer films with thickness of two layers (10 $\AA$ ) and the near-absence of finite-size effects in these two-dimensional ferroelectrics which may be generated by coupling only within the plane of the film [66]. Recent $a b$ initio studies have confirmed the possibility of retaining the ferroelectricity in ultra-thin films, and suggested the absence of the critical size effect [67] [68].

On the other hand, Junquera and Ghosez reported first-principle calculations on a realistic model of perovskite thin films with metallic electrodes. They showed that $\mathrm{BaTiO}_{3}$ films with $\mathrm{SrRuO}_{3}$ electrodes have the critical thickness of 6 unit cells ( $\sim 24 \AA$ ) and lose the ferroelectricity below this thickness, due to the depolarization field effect at the ferroelectric-metal interfaces (Figure 19) [69].

Recent Raman scattering studies showed that ultra-thin $\mathrm{BaTiO}_{3}$ films grown commensurately on $\mathrm{SrTiO}_{3}$ substrate have a spontaneous polarization as thin as 4 unit cells (16 $\AA$ ) [70]. The ferroelectric phase transition temperature $T_{c}$ is shown as a function of $\mathrm{BaTiO}_{3}$ film thickness in Figure 20. Recent experimental and theoretical works showed the critical thickness is much smaller than those previously reported.

It should be pointed out that the close analogy of ferroelectric behavior between Bi-layered perovskite $\mathrm{SrBi}_{2} \mathrm{Ta}_{2} \mathrm{O}_{9}$ and thin film of so-called typical ferroelectric perovskite $\mathrm{BaTiO}_{3}$. The layered ferroelectric $\mathrm{SrBi}_{2} \mathrm{Ta}_{2} \mathrm{O}_{9}$ is a bulk crystal itself, but is considered to be a good example of ultra-thin ferroelectric model with

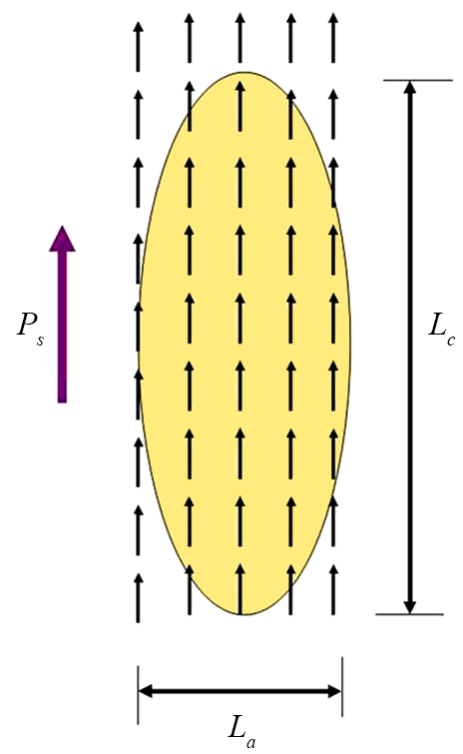

Figure 18. A sketch of ferroelectric correlation region in dipolar materials [64]. 


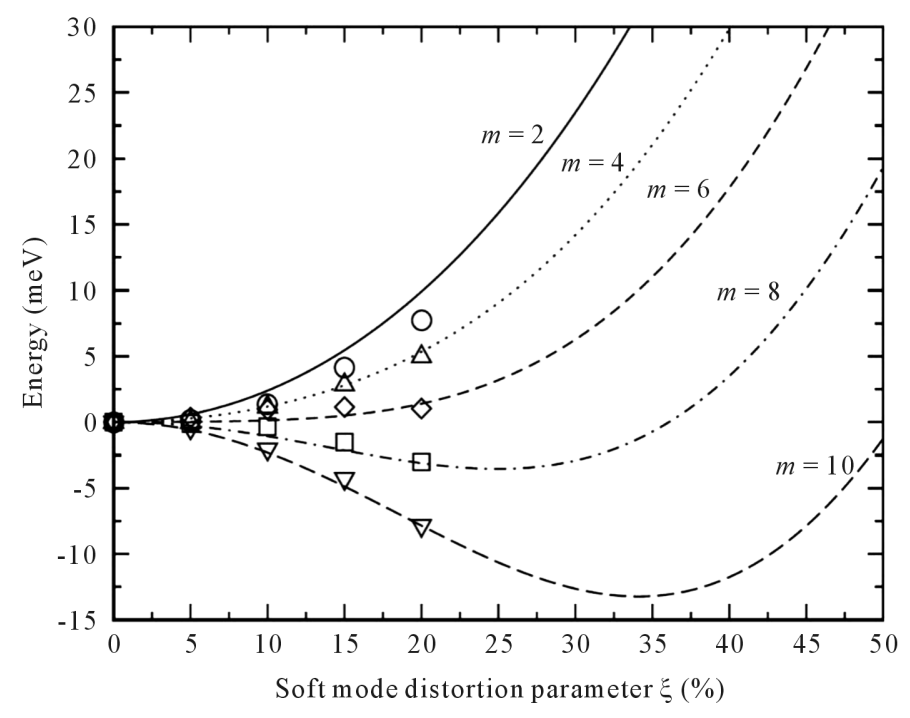

Figure 19. First-principles calculations of the energy of $\mathrm{BaTiO}_{3}$ ferroelectric films with $m$ unit cells as a function of the soft-mode distortion $\xi$ [68].

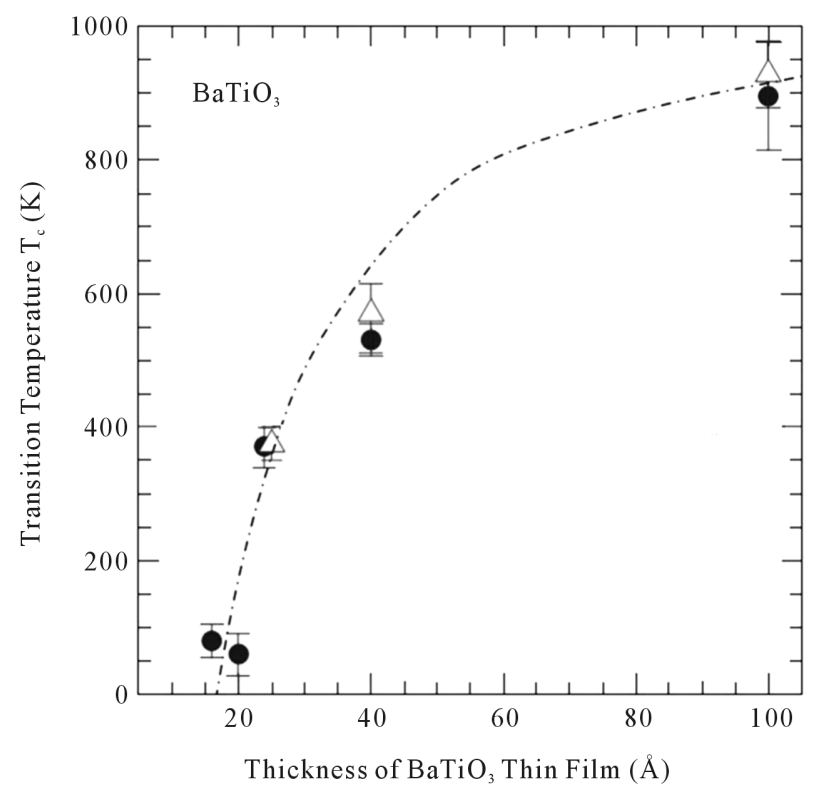

Figure 20. The plot of the ferroelectric phase transition temperature $T_{\mathrm{c}}$ versus film thickness of $\mathrm{BaTiO}_{3}$ films grown on $\mathrm{SrTiO}_{3}$ substrates, observed by Raman scattering [69].

two monolayers of perovskite $\mathrm{TaO}_{6}$ units, free from any misfit lattice strain and interface charge layer with electrodes. We summarized recent dielectric properties of Bi-layered perovskites and discuss the analogy of these two types of ferroelectrics.

\section{Critical Thickness}

As $\mathrm{Sr}_{2} \mathrm{Bi}_{4} \mathrm{Ti}_{5} \mathrm{O}_{18}$ is a compound with five perovskite layers sandwiched by $\mathrm{Bi}_{2} \mathrm{O}_{2}$ semiconducting layers, it is considered as a model of thin film with five perovskite unit cells. While the ferroelectricity of thin films may be suppressed below six unit cells after Junquera and Ghosez [67], $\mathrm{Sr}_{2} \mathrm{Bi}_{4} \mathrm{Ti}_{5} \mathrm{O}_{18}$ shows ferroelectricity along the $a$-axis, but not along the tetragonal $c$-axis. Similar dielectric properties have been observed in $\mathrm{SrBi}_{2} \mathrm{Ta}_{2} \mathrm{O}_{9}$ which 
have two perovskites. The spontaneous polarization appears along the $a$-axis and the dielectric constant shows rather weak temperature dependence. Even in the case of $\mathrm{SrBi}_{2} \mathrm{Ta}_{2} \mathrm{O}_{9}(m=2)$ and $\mathrm{Sr}_{2} \mathrm{Bi}_{4} \mathrm{Ti}_{5} \mathrm{O}_{18}(m=5)$, the soft mode still exists, although it becomes to be highly overdamped near $T_{\mathrm{c}}$ and additional relaxation modes appear.

According to the calculations of local field by Luttinger and Tisza [71], the strong ferroelectric interaction between $\mathrm{Ti}$ (or $\mathrm{Ta}$ ) ions and $\mathrm{O}$ ions appears along the tetragonal $c$-axis. Although the strongly correlated -O-Ti-O-Ti-O- chain plays an important role for the appearance of ferroelectricity in bulk $\mathrm{BaTiO}_{3}$ [63], the -O-Ta-O-Ta-O- chain along the pseudo-tetragonal $c$ axis is interrupted by the existence of semiconductor $\mathrm{Bi}_{2} \mathrm{O}_{2}$ layers in $\mathrm{SrBi}_{2} \mathrm{Ta}_{2} \mathrm{O}_{9}$. The strength of interaction between $\mathrm{Ti}$ ion and adjacent $\mathrm{O}$ ions is half, but antiferroelectric in the $a-b$ plane after Luttinger and Tisza. However, the configuration of distortion parameter $p$ in Figure 10 suggests us that the interaction is strong but antiferroelectric along the pseudo tetragonal $c$-axis, and ferroelectric along the $a$-axis in $\mathrm{SrBi}_{2} \mathrm{Ta}_{2} \mathrm{O}_{9}$. It is expected that a crossover of ferroelectric to antiferroelectric interaction will be realized in thin films of $\mathrm{BaTiO}_{3}$, considering the similarity of dielectric properties between $\mathrm{SrBi}_{2} \mathrm{Ta}_{2} \mathrm{O}_{9}$ bulk crystal and thin $\mathrm{BaTiO}_{3}$ films mentioned above. It might be expected that the canted arrangement of dipole moments may be induced even in thin $\mathrm{BaTiO}_{3}$ films by the two-dimensionality.

The suppression of ferroelectricity has been reported for nana-particles of $\mathrm{BaTiO}_{3}$ and $\mathrm{PbTiO}_{3}$, where the critical size is $20 \sim 30$ unit cells [72]. However the dipole-dipole interactions within plane are retained and contribute to ferroelectric activity in the case of thin films.

\section{Summary}

The dielectric and structural analogy between Bi-layered perovskites and ferroelectric thin films suggests that the bulk Bi-layered ferroelectrics are a good model of ferroelectric ultra-thin films with a few layers of perovskite units, free from any misfit lattice strain with substrate and surface charges at the interface with electrodes. In ultra-thin perovskite films, ferroelectric interactions are still prominent and the octahedra prefer an antiferroelectric arrangement rather than ferroelectric one along the tetragonal or pseudo-tetragonal axis (normal to the plane). In the case of a few layers less than $m=6$, octahedra have a dipole moment, though first principles calculation suggests the soft-mode distortion $\xi=0$, i.e. a non-polar structure [68]. The soft mode may exist even in ultra-thin films but changes to be highly overdamped near the ferroelectric phase transition temperature $T_{c}$. Moreover an additional relaxation mode is induced, which means an occurrence of coupling with displacive

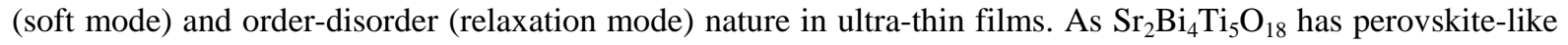
groups less than six unit cells, it is a critical material whether the ferroelectricity persists or not. The mechanism mentioned above might be applicable for $\mathrm{SrBi}_{2} \mathrm{Ta}_{2} \mathrm{O}_{9}$ with two perovskite units $(m=2)$ and $\mathrm{Sr}_{2} \mathrm{Bi}_{4} \mathrm{Ti}_{5} \mathrm{O}_{18}$ with five perovskite groups $(m=5)$, because of the close similarity in dielectric behavior. Based on experiments on Bi-layered perovskites, it may be possible that there is no critical thickness for the appearance of ferroelectricity in ferroelectric thin films in principle.

\section{References}

[1] A-Paz de Marajo, C., Cushier, J.D., McMillan, L.D., Scott, M.C. and Scott, J.F. (1995) Fatigue-Free Ferroelectric Capacitors with Platinum Electrodes. Nature, 374, 627-629. http://dx.doi.org/10.1038/374627a0

[2] Scott, J.F. (1998) NANO-Phase SBT-Family Ferroelectric Memories. Ferroelectrics Review, 1, 1-14. http://dx.doi.org/10.1080/10584589808202046

[3] Uchino, K. (2000) Ferroelectric Devices. Marcel Dekker, New York.

[4] Okuyama, M. and Ishibashi, Y. (2005) Ferroelectric Thin Films. Springer-Verlag, Berlin, Heidelberg, New York.

[5] Dauber, M., Raba, K.M. and Scott, J.F. (2005) Physics of Thin-Film Ferroelectric Oxides. Reviews of Modern Physics, 77, 1083. http://dx.doi.org/10.1103/RevModPhys.77.1083

[6] Batra, I.P. and Silverman, B.D. (1972) Thermodynamic Stability of Thin Ferroelectric Films. Solid State Communications, 11, 291-294. http://dx.doi.org/10.1016/0038-1098(72)91180-5

[7] Kretschmer, R. and Binder, K. (1979) Surface Effects on Phase Transitions in Ferroelectrics and Dipolar Magnets. Physical Review B, 20, 1065. http://dx.doi.org/10.1103/PhysRevB.20.1065

[8] Tilley, D. (1996) Ferroelectric Thin Films. Gordon and Breach, Amsterdam, 12.

[9] Onodera, A., Fukunaga, M. and Takesada, M. (2012) Ferroelectric Instability and Dimensionality in Bi-Layered Perovskites and Thin Films. Advances in Condensed Matter Physics, 2012, Article ID: 714625.

http://dx.doi.org/10.1155/2012/714625 
[10] Merz, W.J. (1949) The Electric and Optical Behavior of BaTi Single-Domain Crystals. Physical Review, 76, 1221.

[11] Cochran, W. (1960) Crystal Stability and the Theory of Ferroelectricity. Advances in Physics, 9, 387-423. http://dx.doi.org/10.1080/00018736000101229

[12] Cochran, W. (1961) Crystal Stability and the Theory of Ferroelectricity Part II. Piezoelectric Crystals. Advances in Physics, 10, 401-420. http://dx.doi.org/10.1080/00018736100101321

[13] Yoneda, Y., Kasatani, H., Terauchi, H., Yano, Y., Terashima, T. and Bando, Y. (1993) Ferroelectric Phase Transition in $\mathrm{BaTiO}_{3}$ Films. Journal of the Physical Society of Japan, 62, 1840-1843. http://dx.doi.org/10.1143/JPSJ.62.1840

[14] Terauchi, H., Yoneda, Y., Watanabe, Y., Kasatani, H., Sakaue, K., Kamigaki, K., Iijima, K., Yano, Y., Terashima, T. and Bando, Y. (1994) Epitaxial $\mathrm{BaTiO}_{3}$ Crystals. Section I: Invited and Orally Presented Papers: Section Ia: Thin films: Experiment and Application. Ferroelectrics, 151, 21-26. http://dx.doi.org/10.1080/00150199408244718

[15] Yoneda, Y., Kasatani, H., Terauchi, H., Yano, Y., Terashima, T. and Bando, Y. (1995) Ferroelectric Phase Transition in $\mathrm{BaTiO}_{3}$ Films. Journal of Crystal Growth, 150, 1090-1093. http://dx.doi.org/10.1080/00150199408244718

[16] Iijima, K., Terashima, T., Bando, Y., Kamigaki, K. and Terauchi, H. (1992) Atomic Layer Growth of Oxide Thin Films with Perovskite-Type Structure by Reactive Evaporation. Journal of Applied Physics, 72, 2840-2845. http://dx.doi.org/10.1063/1.351536

[17] Yano, Y., Iijima, K., Daitoh, Y., Terashima, T., Bando, Y., Watanabe, Y., Kasatani, H. and Terauchi, H. (1994) Epitaxial Growth and Dielectric Properties of $\mathrm{BaTiO}_{3}$ Films on Pt Electrodes by Reactive Evaporation. Journal of Applied Physics, 76, 7833-7838. http://dx.doi.org/10.1063/1.357891

[18] Terauchi, H., Watanabe, Y., Kasatani, H., Kamigaki, K., Yano, Y., Terashima, T. and Bando, Y. (1992) Structural Study of Epitaxial $\mathrm{BaTiO}_{3}$ Crystals. Journal of the Physical Society of Japan, 61, 2194-2197. http://dx.doi.org/10.1143/JPSJ.61.2194

[19] Terauchi, H., Watanabe, Y., Kasatani, H., Kamigaki, K., Terashima, T. and Bando, Y. (1992) X-Ray Studies on Single Crystal Films of $\mathrm{BaTiO}_{3}$. Ferroelectrics, 137, 33-38. http://dx.doi.org/10.1080/00150199208015934

[20] Grabovsky, S.V., Shnaidshtein, I.V., Takesada, M., Onodera, A. and Strukov, B.A. (2013) Calorimetric Study of Ferroelectric $\mathrm{BaTiO}_{3}$ in Cubic Phase. Journal of Advanced Dielectrics, 3, 1350032. http://dx.doi.org/10.1142/S2010135X1350032X

[21] Onodera, A., Kawamura, Y., Okabe, T. and Terauchi, H. (1999) Specific Heat in Ferroelectric BaTiO 3 Epitaxial Thin Films. Journal of the European Ceramic Society, 19, 1477-1480. http://dx.doi.org/10.1016/S0955-2219(98)00457-9

[22] Aurivillius, B. (1949) Mixed Bismuth Oxides with Layer Lattices. 1. The Structure Type of $\mathrm{CaNb}_{2} \mathrm{Bi}_{2} \mathrm{O}_{9}$. Arki for Kemi, 1, 463-480.

[23] Smolensky, G.A., Isupov, V.A. and Agranovskaya, A.I. (1961) Ferroelectrics of the Oxygen-Octahedral Type with Layered Structure. Soviet Physics, Solid State, 3, 651-655.

[24] Haeni, J.H., Theis, C.D., Schlom, D.G., Tian, W., Pan, X.Q., Cheng, H., Takeuchi, I. and Xiang, X.D. (2001) Epitaxial Growth of the First Five Members of the $\mathrm{Sr}_{n+1} \mathrm{Ti}_{n} \mathrm{O}_{3 \mathrm{n}+1}$ Ruddlesden-Popper Homologous Series. Applied Physics Letters, 78, 3292-3294. http://dx.doi.org/10.1063/1.1371788

[25] Subbarao, E.C. (1962) A Family of Ferroelectric Bismuth Compounds. Journal of Physics and Chemistry of Solids, 23, 665-676. http://dx.doi.org/10.1016/0022-3697(62)90526-7

[26] Shiozaki, Y., Nakamura, E., Mitsui, T., et al. (2002) Ferroelectrics and Related Substances, Landolt-Bornstein New Series III-39, Subvolume A2: Oxides. Springer-Verlag, Berlin, 245.

Nakamura, E., Mitsui, T., Adachi, M., Akishige, Y., Deguchi, K., Harada, J., Ikeda, T., Okuyama, M., Sawaguchi, E., Shiozaki, Y., Toyoda, K., Yamada, T., Gesi, K., Hikita, T., Makita, Y., Shigenari, T., Tatsuzaki, I. and Yagi, T. (1990) Ferroelectrics and Related Substances, Landolt-Bornstein New Series III-28, Subvolume A: Oxides. Springer-Verlag, Berlin, 173.

[27] Onodera, A., Yoshio, K., Myint, C.C., Kojima, S., Yamashita, H. and Takama, T. (1999) Thermal and Structural Studies of Phase Transitions in Layered Perovskite $\mathrm{SrBi}_{2} \mathrm{Ta}_{2} \mathrm{O}_{9}$. Japanese Journal of Applied Physics, 38, 5683. http://dx.doi.org/10.1143/JJAP.38.5683

[28] Onodera, A., Kubo, T., Yoshio, K., Kojima, S., Yamashita, H. and Takama, T. (2000) Crystal Structure of High-Temperature Paraelectric Phase in Bi-Layered Perovskite $\mathrm{Sr}_{0.85} \mathrm{Bi}_{2.1} \mathrm{Ta}_{2} \mathrm{O}_{9}$. Japanese Journal of Applied Physics, 39, 5711. http://dx.doi.org/10.1143/JJAP.39.5711

[29] Onodera, A., Yoshio, K., Myint, C.C., Tanaka, M., Hironaka, K. and Kojima, S. (2000) Thermal Behavior in Ferroelectric $\mathrm{SrBi}_{2} \mathrm{Ta}_{2} \mathrm{O}_{9}$ Thin Films. Ferroelectrics, 241, 159-166. http://dx.doi.org/10.1080/00150190008224987

[30] Yamashita, H., Yoshio, K., Murata, W. and Onodera, A. (2002) Structural Changes and Ferroelectricity in Bi-Layered $\mathrm{SrBi}_{2} \mathrm{Ta}_{2} \mathrm{O}_{9}$. Japanese Journal of Applied Physics, 41, 7076. http://dx.doi.org/10.1143/JJAP.41.7076

[31] Murata, W., Onodera, A., Yoshio, K., Yamashita, H. and Takama, T. (2002) Ferroelectric Phase Transition in Layered 
Perovskite $\mathrm{SrBi}_{2} \mathrm{Ta}_{2} \mathrm{O}_{9}$. Ferroelectrics, 270, 303-308. http://dx.doi.org/10.1080/00150190211190

[32] Onodera, A., Yoshio, K. and Yamashita, H. (2003) Structural Study of Intermediate Phase in Layered Perovskite $\mathrm{SrBi}_{2} \mathrm{Ta}_{2} \mathrm{O}_{9}$ Single Crystal. Japanese Journal of Applied Physics, 42, 6218. http://dx.doi.org/10.1143/JJAP.42.6218

[33] Yoshio, K., Onodera, A. and Yamashita, H. (2003) Ferroelectric Phase Transition and New Intermediate Phase in Bi-Layered Perovskite $\mathrm{SrBi}_{2} \mathrm{Ta}_{2} \mathrm{O}_{9}$. Ferroelectrics, 284, 65-74. http://dx.doi.org/10.1080/00150190390204718

[34] Wemple, S.H., Didomenico Jr., M. and Camlibel, I. (1968) Dielectric and Optical Properties of Melt-Grown BaTiO 3 . Journal of Physics and Chemistry of Solids, 29, 1797-1803. http://dx.doi.org/10.1016/0022-3697(68)90164-9

[35] Rae, A.D., Thompson, J.G. and Withers, R.L. (1992) Structure Refinement of Commensurately Modulated Bismuth Strontium Tantalate, $\mathrm{Bi}_{2} \mathrm{SrTa}_{2} \mathrm{O}_{9}$. Acta Crystallographica Section B, B48, 418-428. http://dx.doi.org/10.1107/S0108768192001654

[36] Shimakawa, Y., Kubo, Y., Nakagawa, Y., Kamiyama, T., Asano, H. and Izumi, F. (1998) Crystal Structures and Ferroelectric Properties of $\mathrm{SrBi}_{2} \mathrm{Ta}_{2} \mathrm{O}_{9}$ and $\mathrm{Sr}_{0.8} \mathrm{Bi}_{2.2} \mathrm{Ta}_{2} \mathrm{O}_{9}$. Applied Physics Letters, 74, 1904-1906. http://dx.doi.org/10.1063/1.123708

[37] Miura, K. (2002) Electronic Properties of Ferroelectric $\mathrm{SrBi}_{2} \mathrm{Ta}_{2} \mathrm{O}_{9}, \mathrm{SrBi}_{2} \mathrm{Nb}_{2} \mathrm{O}_{9}$, and $\mathrm{PbBi}_{2} \mathrm{Nb}_{2} \mathrm{O}_{9}$ with Optimized Structures. Applied Physics Letters, 80, 2967-2969. http://dx.doi.org/10.1063/1.1474607

[38] Yoshio, K., Matsubara, I., Yamada, A., Onodera, A., Sakai, A. and Yamashita, H. (2003) Phase Transition in Ferroelectric $\mathrm{SrBi}_{2} \mathrm{Ta}_{2} \mathrm{O}_{9}$ Single Crystal. Journal of the Korean Physical Society, 43, S1034-S1037.

[39] Moriya, T. (1963) Magnetism. Academic Press, New York, 85.

[40] De Gennes, P.-G. (1960) Effects of Double Exchange in Magnetic Crystals. Physical Review, 118, 141-154. http://dx.doi.org/10.1103/PhysRev.118.141

[41] Kittel, C. (1951) Theory of Antiferroelectric Crystals. Physical Review, 82, 729-732. http://dx.doi.org/10.1103/PhysRev.82.729

[42] Tagantsev, A.K., Pertsev, N.A., Muralt, P. and Setter, N. (2001) Strain-Induced Diffuse Dielectric Anomaly and Critical Point in Perovskite Ferroelectric Thin Films. Physical Review B, 65, 012104. http://dx.doi.org/10.1103/PhysRevB.65.012104

[43] Kennedy, B.J., Zhou, Q., Ismunandar, Kubota, Y. and Kato, K. (2008) Cation Disorder and Phase Transitions in the Four-Layer Ferroelectric Aurivillius Phases $\mathrm{ABi}_{4} \mathrm{Ti}_{4} \mathrm{O}_{15}(\mathrm{~A}=\mathrm{Ca}, \mathrm{Sr}, \mathrm{Ba}, \mathrm{Pb})$. Journal of Solid State Chemistry, 181, 1377-1386. http://dx.doi.org/10.1016/j.jssc.2008.02.015

[44] Fukunaga, M. (2008) Private Communication.

[45] Onodera, A., Mouri, S., Fukunaga, M., Hiramatsu, S., Takesada, M. and Yamashita, H. (2006) Phase Transition in Bi-Layered Oxides with Five Perovskite Layers. Japanese Journal of Applied Physics, 45, 9125. http://dx.doi.org/10.1143/JJAP.45.9125

[46] Mouri, S., Fukunaga, M., Hiramatsu, S., Takesada, M. and Onodera, A. (2007) Ferroelectric Phase Transition in Bi-Layered Perovskite $\mathrm{Sr}_{2} \mathrm{Bi}_{4} \mathrm{Ti}_{5} \mathrm{O}_{18}$. Ferroelectrics, 346, 93-96. http://dx.doi.org/10.1080/00150190601180406

[47] Onodera, A., Mouri, S., Fukunaga, M., Takesada, M. and Yamashita, H. (2007) Phase Transition in Bi-Layered Perovskite and a Model of Ultra-Thin Ferroelectric Film. Ferroelectrics, 346, 25-31. http://dx.doi.org/10.1080/00150190601180117

[48] Hwang, C.S. (2002) Thickness-Dependent Dielectric Constants of (Ba,Sr) $\mathrm{TiO}_{3}$ Thin Films with Pt or Conducting Oxide Electrodes. Journal of Applied Physics, 92, 432-437. http://dx.doi.org/10.1063/1.1483105

[49] Kojima, S. (1998) Optical Mode Softening of Ferroelectric and Related Bismuth Layer-Structured Oxides. Journal of Physics: Condensed Matter, 10, L327. http://dx.doi.org/10.1088/0953-8984/10/20/003

[50] Kojima, S., Imaizumi, R., Hamazaki, S. and Takashige, M. (1994) Raman Scattering Study of Bismuth Layer-Structure Ferroelectrics. Japanese Journal of Applied Physics, 33, 5559. http://dx.doi.org/10.1143/JJAP.33.5559

[51] Ko, J.-H., Hushur, A., Kojima, S., Sih, B.C. and Ye, Z.-G. (2002) Acoustic Anomalies and Central Peak in $\mathrm{SrBi}_{2} \mathrm{Ta}_{2} \mathrm{O}_{9}$ Single Crystals Studied by Micro-Brillouin Scattering. Applied Physics Letters, 81, 4043-4045. http://dx.doi.org/10.1063/1.1524036

[52] Almeida, A., Chaves, M.R., Amorin, H., Costa, M.E.V. and Kholkin, A.L. (2005) Lattice Dynamics Study of HighQuality Strontium Bismuth Tantalate Single Crystals. Journal of Physics: Condensed Matter, 17, 7605. http://dx.doi.org/10.1088/0953-8984/17/48/012

[53] Takesada, M., Sutoh, K., Fukunaga, M. and Onodera, A. (2007) Light Scattering Study of Bismuth Layered Ferroelectric $\mathrm{SrBi}_{2} \mathrm{Ta}_{2} \mathrm{O}_{9}$. Ferroelectrics, 355, 149-153. http://dx.doi.org/10.1080/00150190701517655

[54] Isumunandar, T.K., Hoshikawa, A., Zhou, Q., Kennedy, B.J., Kubota, Y. and Kato, K. (2004) Structural Studies of Five Layer Aurivillius Oxides: $\mathrm{A}_{2} \mathrm{Bi}_{4} \mathrm{Ti}_{5} \mathrm{O}_{18}(\mathrm{~A}=\mathrm{Ca}$, Sr, Ba and $\mathrm{Pb})$. Journal of Solid State Chemistry, 177, 4188-4196. http://dx.doi.org/10.1016/j.jssc.2004.07.032 
[55] Kojima, S. (1994) Raman Scattering Study of Bismuth Layer-Structure Ferroelectrics. Japanese Journal of Applied Physics, 33, 5559. http://dx.doi.org/10.1143/JJAP.33.5559

[56] Fukunaga, M. (2009) Soft Mode and Relaxation Behavior in Two-Dimensional Ferroelectric Bi-Layered Perovskites. Doctor Thesis, Hokkaido University, Sapporo.

[57] Comes, R., Lambert, M. and Guinier, A. (1968) The Chain Structure of $\mathrm{BaTiO}_{3}$ and $\mathrm{KNbO}_{3}$. Solid State Communications, 6, 715-719. http://dx.doi.org/10.1016/0038-1098(68)90571-1

[58] Comes, R., Lambert, M. and Guinier, A. (1970) Désordre linéaire dans les cristaux (cas du silicium, du quartz, et des pérovskites ferroélectriques). Acta Crystallographica Section A, 26, 244-254. http://dx.doi.org/10.1107/S056773947000061X

[59] Comes, R., Lambert, M. and Guiner, A. (1970) Structural Disorder of $\mathrm{BaTiO}_{3}$ Type Ferroelectrics. Journal of the Physical Society of Japan, 28, 195-198.

[60] Stern, E.A. (2004) Character of Order-Disorder and Displacive Components in Barium Titanate. Physical Review Letters, 93, 037601. http://dx.doi.org/10.1103/PhysRevLett.93.037601

[61] Zalar, B., Laguta, V.V. and Blinc, R. (2003) NMR Evidence for the Coexistence of Order-Disorder and Displacive Components in Barium Titanate. Physical Review Letters, 90, 037601. http://dx.doi.org/10.1103/PhysRevLett.90.037601

[62] Blinc, R. (2011) Advance Ferroelectricity. Oxford University Press, Oxford, 15. http://dx.doi.org/10.1093/acprof:oso/9780199570942.001.0001

[63] Slater, J.C. (1950) The Lorentz Correction in Barium Titanate. Physical Review, 78, 748. http://dx.doi.org/10.1103/PhysRev.78.748

[64] Lines, M.E. and Glass, A.M. (1977) Principles and Applications of Ferroelectrics and Related Materials. Clarendon Press, Oxford, 525.

[65] Tybell, Th., Ahn, C.H. and Triscone, J.-M. (1999) Ferroelectricity in Thin Perovskite Films. Applied Physics Letters, 75, 856-858. http://dx.doi.org/10.1063/1.124536

[66] Bune, A.V., Fridkin, V.M., Ducharme, S., Blinov, L.M., Palto, S.P., Sorokin, A.V., Yudin, S.G. and Zlatkin, A. (1998) Two-Dimensional Ferroelectric Films. Nature, 391, 874-877. http://dx.doi.org/10.1038/36069

[67] Ghosez, Ph. and Rabe, K.M. (2000) Microscopic Model of Ferroelectricity in Stress-Free $\mathrm{PbTiO}_{3}$ Ultrathin Films. Applied Physics Letters, 76, 2767-2769. http://dx.doi.org/10.1063/1.126469

[68] Meyer, B. and Vanderbilt, D. (2001) Ab Initio Study of $\mathrm{BaTiO}_{3}$ and $\mathrm{PbTiO}_{3}$ Surfaces in External Electric Fields. Physical Review B, 63, 205426. http://dx.doi.org/10.1103/PhysRevB.63.205426

[69] Junquera, J. and Ghosez, Ph. (2003) Critical Thickness for Ferroelectricity in Perovskite Ultrathin Films. Nature, 422, 506-509. http://dx.doi.org/10.1038/nature01501

[70] Tenne, D.A., Turner, P., Schmidt, J.D., Biegalski, M., Li, Y.L., Chen, L.Q., Soukiassian, A., Trolier-McKinstry, S., Schlom, D.G., Xi, X.X., Fong, D.D., Fuoss, P.H., Eastman, J.A., Syephenson, G.B., Thompson, C.T. and Streiffer, S.K. (2009) Ferroelectricity in Ultrathin $\mathrm{BaTiO}_{3}$ Films: Probing the Size Effect by Ultraviolet Raman Spectroscopy. Physical Review Letters, 103, 177601. http://dx.doi.org/10.1103/PhysRevLett.103.177601

[71] Luttinger, J.M. and Tisza, L. (1946) Theory of Dipole Interaction in Crystals. Physical Review, 70, 954-964. http://dx.doi.org/10.1103/PhysRev.70.954

[72] Ishikawa, K., Nomura, T., Okada, N. and Takada, K. (1996) Size Effect on the Phase Transition in PbTiO 3 Fine Particles. Japanese Journal of Applied Physics, 35, 5196. http://dx.doi.org/10.1143/JJAP.35.5196 


\section{Submit or recommend next manuscript to SCIRP and we will provide best service for you:}

Accepting pre-submission inquiries through Email, Facebook, LinkedIn, Twitter, etc.

A wide selection of journals (inclusive of 9 subjects, more than 200 journals)

Providing 24-hour high-quality service

User-friendly online submission system

Fair and swift peer-review system

Efficient typesetting and proofreading procedure

Display of the result of downloads and visits, as well as the number of cited articles

Maximum dissemination of your research work

Submit your manuscript at: http://papersubmission.scirp.org/ 